\title{
LAS ESTACIONES REALES DURANTE EL PERIODO AQUEMÉNIDA
}

\author{
THE ROYAL STATIONS IN THE ACHAEMENID PERIOD
}

JOAQUÍN VELÁZQUEZ MUÑOZ

\section{INTRODUCCIÓN}

La capacidad del Estado aqueménida para controlar los territorios conquistados, proclamar su presencia, recolectar y supervisar sus bienes, y mantener la seguridad, dependía de un sistema eficaz de comunicación. Aunque el poder fue transferido a los gobernadores provinciales, la vigilancia política de la periferia desde el centro, el movimiento y las operaciones de los ejércitos reales, y la circulación de recursos en forma de tributos y de mercancías exigió la existencia de un sistema de comunicación y de transporte eficiente. El imperio gobernado por los monarcas aqueménidas fue así unido por una extensa red de caminos (Fig. 1). Los grandes centros de poder del imperio fueron así conectados por un sistema viario que agilizaba y facilitaba el transporte de las órdenes reales, así como la circulación de los funcionarios. Sobre esta red se implantó un sistema de correos que permitía al Gran Rey comunicarse con los centros más distantes de su imperio en un

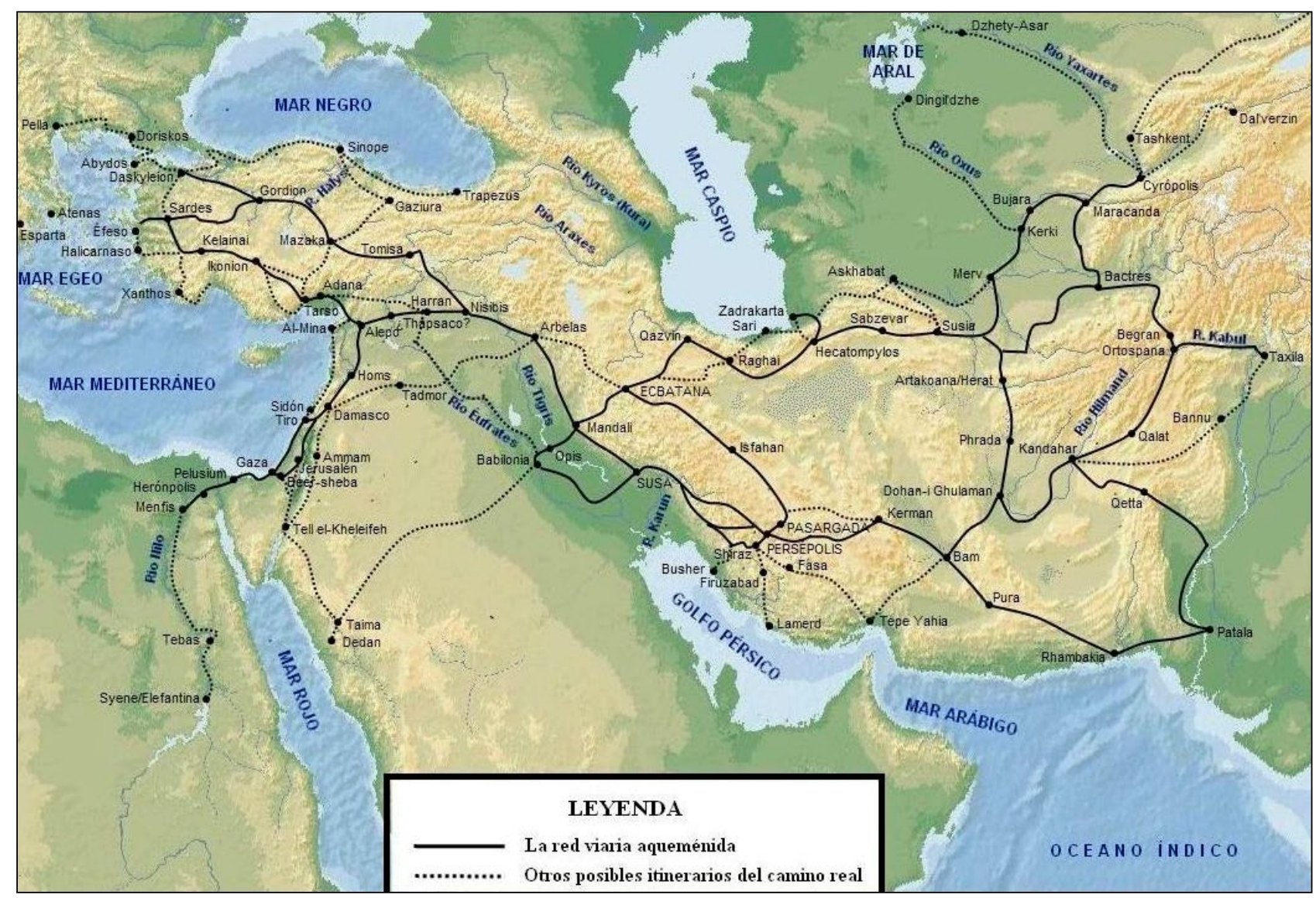

Figura 1: El sistema de caminos reales en el Imperio Persa Aqueménida. 
tiempo record, agilizando por ello la administración de este enorme imperio.

Con ese fin, se implantaron a lo largo de los caminos reales aqueménidas una serie de instalaciones, conocidas genéricamente con el nombre de estaciones, donde los mensajeros reales, funcionarios y trabajadores del Estado, cortesanos y viajeros ordinarios podían alimentarse, descansar y cambiar de montura para poder proseguir su camino sin problemas. Sin embargo, el disfrute de tales ventajas estaba supeditado a la presentación de un documento oficial sellado conocido como halmi (elamita) o miyatukkaš (elamita) en la documentación procedente del Archivo de la Fortificación de Persépolis. Se conoce también la existencia de estas instalaciones gracias al relato de Heródoto (V, 52-54), quien indica que a lo largo del camino real se emplazaron una serie de instalaciones destinadas a dar cobijo y suministro a las personas que, tras presentar su correspondiente autorización sellada, tenían el derecho de disfrute de las prestaciones que ofrecían estas instalaciones.

\section{DENOMINACIÓN DE LAS ESTACIONES}

En cuanto al término que los persas utilizaron para referirse a estas instalaciones no nos ha llegado. Los textos del Archivo de la Fortificación de Persépolis, por ejemplo, mencionan solamente el lugar en el que los viajeros recibieron sus raciones:

«4,65 BAR de harina, recibida por Dauma. Cada uno de los 23 hombres recibió 1,5 QA, y 1 QA por cada «muchacho». Dauma llevaba un documento sellado de Irdarpirna. Ellos viajaron desde Sardes. Ellos iban a Persépolis. Noveno mes del vigésimo séptimo año. En Hidali» (PF 1404).

Las fuentes de época clásica no nos ayudan tampoco mucho en este sentido, pues utilizan para nombrar a estas instalaciones términos de origen griego, como

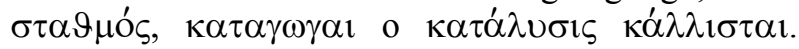
Tampoco los términos utilizados en acadio por los asirios para referirse a sus «estaciones postales» (kalliu, kalliju) y «estaciones de descanso» (bit mardìtu) nos ayudan en esta tarea. En la carta del sátrapa de Egipto Aršāma a su intendente Nehtihôr, se utiliza el término arameo ' $d w n$ (VI, 5), que P. Grelot tradujo como «(estación de) viaje o camino» (DAE 67). Esta carta señala cómo los diferentes funcionarios recibieron la orden de suministrar con raciones a Nehtihôr, a sus acompañantes y a sus caballos en cada ' $d w n$ que «desde provincia en provincia atravesara hasta que llegara a Egipto». La traducción de Grelot de este término está basada posiblemente en las palabras avésticas advan, que aparece en los Gathas, y a $\delta$ wan-, en el Avesta, que han sido traducidas como "senda, carretera, camino» (Greenfield, 1982, 10). Este empleo de ' $d w n$ evoca inevitablemente al 'awānā citado en el arameo babilónico, y que venía a significar claramente «estación, morada, lugar de reposo» (la mansio latina), e incluso «morada funeraria», aunque en el arameo babilónico judío el término se limita a señalar una medida de distancia ( $«$ hasta Jerusalén hay muchas estaciones del camino»: BT Nazir 7a) o a un lugar donde uno podía obtener alimentos a lo largo del camino (BM 79b=AZ 65a).

F. Rundgren ha ofrecido como posible etimología del iraní el término 'awwānā como una temprana contaminación de dos antiguas palabras iranias, àvahana «aldea» $\mathrm{y} *$ *avāhana «lugar donde uno podía desensillar a los caballos $\rangle^{1}$. ¿No se puede asumir un desarrollo del término en antiguo persa adwana $>$ *awānā «viaje, camino» de una manera similar a la palabra en antiguo persa *hadabāra > ayār, en persa moderno, puesto que esta palabra también influenció en el significado del 'awânâ arameo especialmente utilizado en el Talmud babilónico? Como información adicional, los caminos de la Persia pre-Islámica también fueron abastecidos con estaciones del camino o de «mesones»; en persa medio fueron conocidas como aspinj, en judío arameo como ǔ̌p $\overline{\imath z}$ y en mandaico como špinza. El término sobrevive en el persa moderno como sipanj. En un episodio registrado en el Talmud babilónico, oímos hablar de un mensajero real sasánida que paró en un mesón (ušpizza $)$ en su camino para detener a un erudito judío bien conocido (Babā Mesī'ā, 86a); además, el término ušpizkān («mesonero») se encuentra en el Talmud y en otros contextos (Silverstain, 2007, 28). El término pre-Islámico para el «mesón» continuó siendo utilizado en la Sogdiana Omeya, donde la palabra arspanj, una variación local del persa medio aspinj, denotó una «estación postal» (Briant, 1996, 368). A pesar de esta variada terminología, los intentos de reconstrucción son ciertamente hipotéticos y sólo nuevos hallazgos nos permitirán conocer como los aqueménidas denominaban a sus estaciones en su propia lengua.

\section{DISTANCIA ENTRE LAS ESTACIONES}

Otra cuestión muy discutida es la distancia existente entre estas instalaciones. Según se desprende de los relatos de las fuentes antiguas éstas estaban situadas a intervalos de unos $25 \mathrm{~km}$ por término medio. El problema radica en sí estas instalaciones servían también como estaciones postales, ya que un mensajero a caballo, por ejemplo, podría cubrir en un día de marcha mayores distancias. Por este motivo se ha esgrimido que las estaciones descritas por Heródoto formaban una red de praetoria reales, mientras que las instalaciones postales debían situarse a mayor distancia las unas de las otras, y por ello, serían construcciones independientes. Como se acaba de mencionar, estas estaciones estaban dispuestas a intervalos de unos 20 a $30 \mathrm{~km}$ a lo largo del camino real aqueménida, aunque

\footnotetext{
1. Rundgren, 1965-1966, 75-79, donde proporciona un útil examen de la etimología de ' $w n$ '. Argumenta debidamente contra la propuesta de una etimología semítica para esta palabra.
} 
lo más probable es que se situaran a un intervalo de un día de marcha, distancia que sería medida según las condiciones orográficas del terreno (Velázquez, 2010, 519). El problema se plantea claramente así: ¿los persas aprovecharon la existencia de estas estaciones para ocuparse de las necesidades de su servicio postal, o instalaron una red de estaciones independientes de estas estaciones reales? Para determinar esta cuestión, dos testimonios deben de ser referidos.

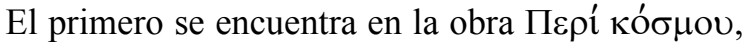
en su capítulo VI. Esta obra ha sido atribuida tradicionalmente a Aristóteles aunque generalmente se considera un trabajo pseudoepigráfico ${ }^{2}$. Este pasaje trata del poder de los reyes persas, Cambises, Darío y Jerjes:

«Todo el Imperio de Asia había sido repartido según los pueblos entre generales, gobernadores y reyesclientes, esclavos del Rey de Reyes, corredores y espias, y entre mensajeros y hombres que vigilan sobre las señales».

Estos últimos cuatro cuerpos de servidores, a los que

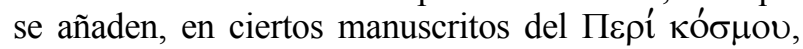
un quinto cuerpo, los escoltas, nos hacen entrever una cuádruple organización sobre los caminos. Tenemos, en primer lugar los mensajeros a pie, que llevan las noticias de menor importancia; los espías, encargados de la recolección de información; los guardias estacionados probablemente como los corredores en cada estación, con la misión de velar por la seguridad de los caminos; los mensajeros del servicio exprés y finalmente aquellos a los que llamamos telegrafistas y sobre quienes apenas sabemos a qué distancia se encontraban los unos de los otros. El hecho de que se mencione en este pasaje la transmisión de las noticias por medio de señales, que requería una instalación especial, hace pensar que, para las estaciones postales, no sería imposible que se hubieran organizado independientemente de las estaciones reales y de las torres de fuego. El segundo pasaje, que nos es transmitido por Diodoro (XIX, 57, 5), no sirve para sacudir esta hipótesis. Dice así de Antígono:

«Dotó, compartiéndolo con todo el Asia, de la que era el amo, de señales de fuego y de correos por medio de los cuales quería llevar rápidamente su ayuda a toda cosa».

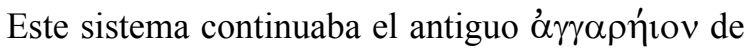
los reyes aqueménidas y nos muestra, también, la diferente disposición de dar las noticias, o bien por medio de fuegos o bien haciéndolos llevar mediante mensajeros a caballo. Lo que hace suponer que el sistema de estaciones postales era una organización independiente es el hecho de que si se admite que algunas estaciones reales albergaban también los establos del

2. Para más información sobre la discusión de la autoría del autor véase Reale, 1974 y Boss, 1991, 312-332. servicio postal, sólo se pueden sugerir distancias comprendidas entre los 50 y los $75 \mathrm{~km}$. Se ha esgrimido que la distancia de $75 \mathrm{~km}$ no puede ser correcta, puesto que para alcanzar esta rapidez era necesario un cambio más frecuente, que no era posible en el periodo aqueménida, puesto que un servicio regular a través de este inmenso territorio habría requerido una organización extremadamente extensa y costosa, puesto que un inmenso número de caballos debería de ser proporcionado por los establos reales para hacer funcionar el servicio correctamente.

Pero, ¿habría cuadrado esto con las intenciones que presidieron su creación? No es creíble que fuera así. Cuando Jenofonte indica que el rey quería ser informado de todo lo que pasaba en las provincias más distantes de su imperio, no es necesario comprender que el mismo quería administrarlas. Hay una diferencia considerable entre el Estado totalitario, se diría hoy, de los ptolomeos y el Imperio mucho más descentralizado de la monarquía aqueménida. Mientras que se concentraba toda la administración de los ptolomeos en Alejandría, la del Imperio aqueménida se delegaba en los gobernadores provinciales (sátrapas), a quienes el Gran Rey daba sus directivas. El soberano aqueménida no quería pues saber todo lo que ocurría en los confines de su Imperio; él quería ser informado solamente de los acontecimientos que de verdad eran importantes. Ni que decir tiene que la posta real aqueménida transmitía sólo las cartas oficiales. Habría sido inconcebible que fuera diferente. Por este motivo, para la defensa de esta tesis, sólo se puede sugerir un intervalo de $50 \mathrm{~km}$. Sin embargo, después de leer a Heródoto y a Jenofonte, quienes remarcan que este medio de transporte era el más rápido de su época, la distancia de $50 \mathrm{~km}$ al día y de $50 \mathrm{~km}$ por la noche, lo que equivale a unos $10 \mathrm{~km}$ por cada dos horas aproximadamente, no parece corresponderse con la información transmitida por estos textos.

De todas formas es más fiable sugerir que las estaciones postales no eran un ente independiente, sino que las instalaciones situadas a lo largo de los caminos reales cumplían ambas funciones. La evidencia nos la muestra, como no, los textos del Archivo de la Fortificación de Persépolis. Por ejemplo, en la estación de Kurdušum, emplazada en un punto sin determinar del camino real aqueménida que unía Susa con Persépolis, nos encontramos con un funcionario, Haturdada. A pesar de que éste es nombrado como proveedor de raciones en 18 textos, la mayoría de ellos no especifican su localización, aunque siempre que ésta se indica, es en Kurdušum donde realiza su actividad. Además, el sello más frecuentemente utilizado en los textos de la serie Q, raciones de viaje, es el sello PFS 10, que aparece en el margen izquierdo de 25 textos $^{3}$. Tres textos,

\footnotetext{
3. PF 1309-11, 1361, 1365-1366, 1401, 1451, 1461-1462, 1474, 1477-1478, 1485, 1488, 1493, 1496, 1499, 1507, 1519-1520, 1522-1523, 1534, 1540.
} 
las PF 1309-1311 mencionan Kurdušum como el lugar en el que la ración fue entregada, mientras que la PF 1309 nombra a Haturdada como proveedor. Los otros 22 textos de la serie Q con el sello PFS 10 no nombran ni el proveedor ni el sitio, pero es más que probable que Kurdušum fuera el sitio en todos los casos, y que Haturdada fuera, probablemente, el proveedor, puesto que no hay indicios que indiquen que este tipo de sello fuera utilizado por otros proveedores. Por este motivo, la presencia del sello identifica claramente tanto al proveedor como el lugar en el que se entregaba la ración. De este modo, vemos a Haturdada entregando raciones, entre los años 27 y 28 del reinado de Darío, tanto a viajeros (PF 1313-1314, 1316, 1322-1328) como a mensajeros a caballo (pirradaziš en elamita; PF 1315, 1319-1321, 1329), por lo que no existe una distinción entre ambos, siendo suministrados en la misma estación, lo que vendría a confirmar que éstas servían tanto para el sistema postal como para atender las necesidades de los viajeros.

Es por lo tanto necesario asignar a la posta aqueménida una rapidez mucho más alta. La cifra definitiva que buscamos debe pues situarse entre los $50 \mathrm{y}$ los $75 \mathrm{~km}$ por día, y entre los 100 y los $150 \mathrm{~km}$ por cada 96 horas, aunque soy más propenso a darle un valor más próximo a los 150 que a los $100 \mathrm{~km}$. Lo que se acaba de decir cuadra muy bien con el viaje a caballo de Catón el viejo, quien desde Brindisi, tardó 5 días en llegar a Roma, cubriendo los $540 \mathrm{~km}$ a una media de $135 \mathrm{~km}$ por cada 24 horas. Si tomamos estos últimos datos como base, obtendríamos para el camino de Sardes a Susa un viaje de cerca de 20 días. Este trayecto duraba 90 días a pie, tal y como afirma Heródoto. Las altas velocidades que los mensajeros podían alcanzar ya mencionadas en el II milenio a.C. en una carta enviada por Hammurabi a un alto funcionario de Larsa. Él indica: «Viajarás día y noche, de modo que puedas llegar a Babilonia en el plazo de dos días» (Ugnad, 1914, no 14); la distancia existente es de cerca de 200 $\mathrm{km}$ en línea recta. De este modo llegó a ser posible recibir mensajes dentro de un tiempo relativamente corto, donde la distancia entre Susa y Babilonia, por ejemplo, podía ser cubierta en un día y medio, lo que representa un promedio de cerca de $150 \mathrm{~km}$ por día (Forbes, 1934, 80).

Además era mucho más eficaz cambiar de caballo a un intervalo de entre 20 y $25 \mathrm{~km}$, ya que una combinación óptima entre velocidad y distancia es ideal para el funcionamiento óptimo del caballo. Los parámetros establecidos por los sistemas de correos a lo largo de la historia fueron elegidos para evitar el estresante calor producido en el animal ante el sobreesfuerzo realizado y para reducir el riesgo de que el caballo cayera desfallecido. De este modo el sistema se orientó a una explotación optimizada del caballo y del jinete, compatible con sus cargas fisiológicas y biomecánicas. Los caballos comprendidos entre los 4 y los 7 años, con una masa corporal de $390 \mathrm{~kg}$, tienen una energía metabólica de 15 a 28 litros de $\mathrm{O}_{2} /$ min cuando galopan a $20 \mathrm{~km} / \mathrm{h}$, lo que correspondería «sólo» al 69\% de su poder aeróbico máximo en el peor de los casos (el total sería de 40,5 litros de $\mathrm{O}_{2} / \mathrm{min}$ ) (Minetti, 2003, 785).

A partir de estos datos sorprende que los caballos necesiten ser substituidos cada hora y media, mientras que una especie menos atlética, como los seres humanos, pueda ejercitarse, con la misma carga metabólica, durante más de 4 horas. Esta resistencia varía entre los caballos de competición y aquellos especímenes destinados a cubrir distancias medio-cortas. Conviene recordar en este punto a Jenofonte (Cirop., VIII, 6.1718), quien menciona que Ciro II «experimentó para encontrar la distancia que un caballo podría cubrir en un día cuando el animal estaba montado pesadamente, y para que no desfalleciera, entonces él erigió estaciones a distancias semejantes». Es importante mencionar como el Estado de los aqueménidas dotó a su sistema de correspondencia de los medios óptimos para su correcto funcionamiento, sin tener ningún conocimiento de la fisiología equina, a excepción de la distancia máxima que podían recorrer y la velocidad máxima que podían alcanzar, reduciendo los posibles riesgos que podían debilitar y causar la muerte de sus caballos.

Estas velocidades no son particularmente impresionantes: las tropas militares podían cubrir unos $30 \mathrm{~km}$ por día, aunque la descripción de Heródoto (V, 50-52) de que los mensajeros postales podían cubrir un itinerario de noventa días sobre el camino real en solamente nueve días, deduce que el sistema postal era aproximadamente diez veces más rápido que los desplazamientos militares, con mensajeros que cubrían hasta $300 \mathrm{~km}$ en un día (Silverstain, 2007, 13). De este modo, aunque Heródoto especifica que las estaciones fueron establecidas en intervalos diarios, éstos estarían calculados según la distancia estimada realizable por los viajeros ordinarios, mientras que los mensajeros postales pasarían a través de las estaciones situadas sobre el camino en numerosas ocasiones a lo largo del día, reemplazando al caballo para que la velocidad no disminuyera y sustituyendo al jinete cuando se precisara para que la información estuviera en continuo movimiento. De los itinerarios registrados en los trabajos, predominantemente, de los autores griegos, es evidente que la distancia entre las estaciones no era uniforme, aunque las distancias entre las regiones, así como el número de estaciones a lo largo de los respectivos itinerarios, fueron calculadas. En promedio, las estaciones fueron emplazadas a cada $20-25 \mathrm{~km}$, y cualquier variación en esta distancia se puede atribuir a las características topográficas de una región, de la localización de las ciudades, o de otras consideraciones, tales como, por ejemplo, la disponibilidad del agua.

\section{LAS ESTACIONES}

Pero, ¿cómo eran estas estaciones? A partir de los relatos de las fuentes antiguas podemos suponer que las 
estaciones reales disponían de diferentes aposentos, que iban desde simples habitaciones para los mensajeros y los viajeros, hasta lujosos salones que utilizaban los grandes dignatarios de la corte y el propio monarca aqueménida en sus desplazamientos a lo largo de su Imperio. No obstante, debemos de abstenernos a la hora de identificar estos emplazamientos donde, por la noche, el rey se detenía en el camino, con los i $\pi \pi \widetilde{\omega} v \varepsilon \varsigma$ que menciona Jenofonte. De hecho, la información que nos transmiten los hallazgos arqueológicos nos permiten confirmar la suntuosidad de algunas de estas instalaciones, así como de aquellas otras que eran mucho más modestas.

\section{«PABELLONES»}

Debemos señalar, en primer lugar, el descubrimiento en Irán, y principalmente en el Fārs, el corazón del reino persa, de una serie de estructuras palaciegas conocidas por la investigación con el nombre de «pabellones». Aunque algunas de estas estructuras halladas parece que formaron parte de un complejo de edificios más amplio, y por ello tuvieron una función en principio distinta al objeto de este estudio, otras, sin embargo, pueden asociarse con este tipo de estaciones suntuosas, destinadas a la corte y a los altos dignatarios del Estado aqueménida.

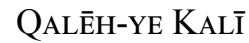

Se han descubierto, por ejemplo, las ruinas de una construcción aqueménida con bases de columna negra de piedra caliza, de forma acampanada y decoradas con flores de loto, en Qalēh-ye Kalī (Tappeh Servan/ Jin-Jin), en la llanura de Rustam-e Yek, en el distrito de Mamasan̄i, en el Fārs occidental, que pueden estar haciendo referencia a la existencia de un pequeño palacio real o a una estación sobre la vía real aqueménida que unía Susa con Persépolis (Stein, 1940, 34-35; Mostafavi, 1967, 13; Kleiss, 1981, 52; Macdermot y Schippmann, 1999, 285; Boucharlat, 2005, 235-236). Las excavaciones recientes en el lugar parecen confirmar el hallazgo, es decir, la existencia de una estación con características palaciegas (Potts et alii, 2007, 287300), ya que si esta edificación fuera simplemente una instalación de almacenamiento en el camino real donde los mensajeros y otros viajeros recibieron sus raciones no habría tenido una arquitectura tan monumental y comparable en estilo a la de Persépolis.

El recinto, por otro lado, se encontraba situado sobre la base de una pequeña elevación montañosa, que a su vez estaba franqueada por un pequeño curso fluvial $^{4}$. Las dimensiones del edificio son de 50 × 30 m;

4. Para las excavaciones en este lugar véase Atarashi y Horiuchi, 1963; Potts et alii, 2007, 287-300; Potts et alii, 2009, 207-282.

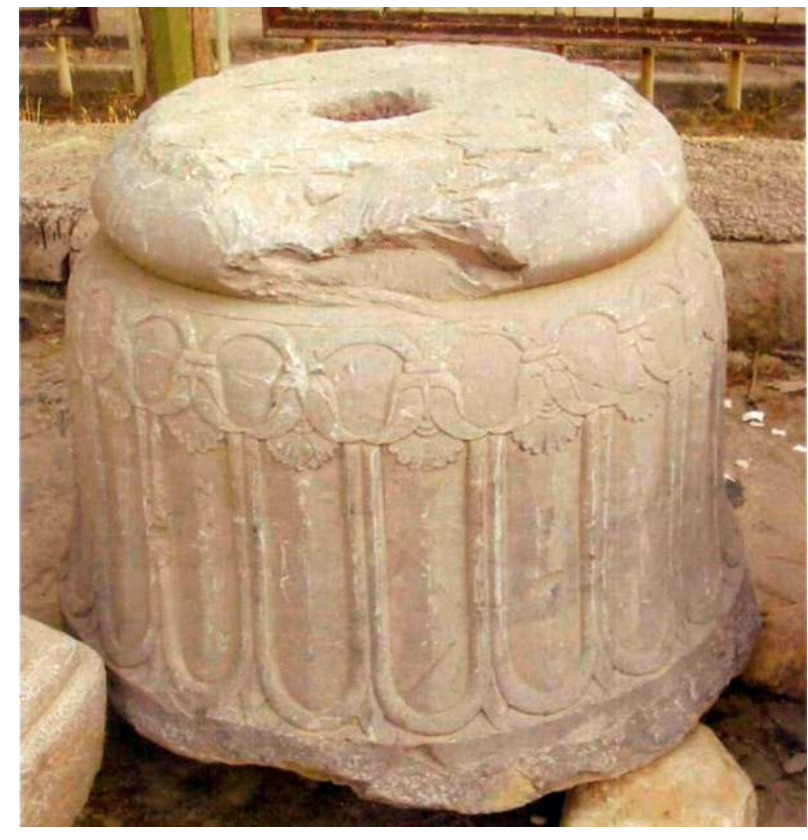

Figura 2: Columna procedente de Qalēh-ye Kalī. D. T. Potts et alii, 2009, 215.

las excavaciones, además, dan prueba de la existencia de bases de columna comparables a las de Persépolis, tanto en forma como en dimensiones, así como en opulencia, evidenciando de este modo que se trataba de un lugar construido específicamente para la corte real, no para el viajero común o para los mensajeros que recorrían los caminos reales. Igualmente, hay que subrayar sus enormes dimensiones, lo que implicaría que el edificio alcanzó una altura considerable. Por ejemplo, la base de columna A-IV, medía $93 \mathrm{~cm}$ de altura y tenía un diámetro de $1,24 \mathrm{~m}$, con un diámetro de superficie superior de $93 \mathrm{~cm}$, mientras que la columna A-I medía 75,8 $\mathrm{cm}$ de altura y tenía un diámetro de $1,25 \mathrm{~m}$, con un diámetro de superficie superior de 79,4 cm (Fig. 2) (Potts et alii, 2007, 295). Estas medidas se comparan razonablemente bien con las dimensiones de las bases de columna utilizadas en la Sala de las 100 Columnas de Persépolis, que medían 98,5 cm de altura y tenían un diámetro de $1,51 \mathrm{~m}$, con un diámetro de superficie superior de $96 \mathrm{~cm}$ (Curtis, 2005, 60). De este modo, parece totalmente ilógico suponer que estas bases, dadas sus dimensiones, apoyaron columnas cortas. Por este motivo, la designación de «pequeño pabellón» utilizada por los primeros excavadores japoneses y muchos comentaristas posteriores debe de ser revisada.

Las piezas, probablemente, formaban parte de las bases de un pórtico o de una entrada más grande, caracterizado por una línea de tres bases de columna, con una cuarta que fue eliminada en la antigüedad (Fig. 3). Estas columnas señalan el límite norte del pórtico, más concretamente de las losas de piedra. Posiblemente, el pórtico original tenía más columnas, sin embargo, el extenso expolio del sitio impide cualquier interpretación sobre este punto. Una posibilidad es que las 


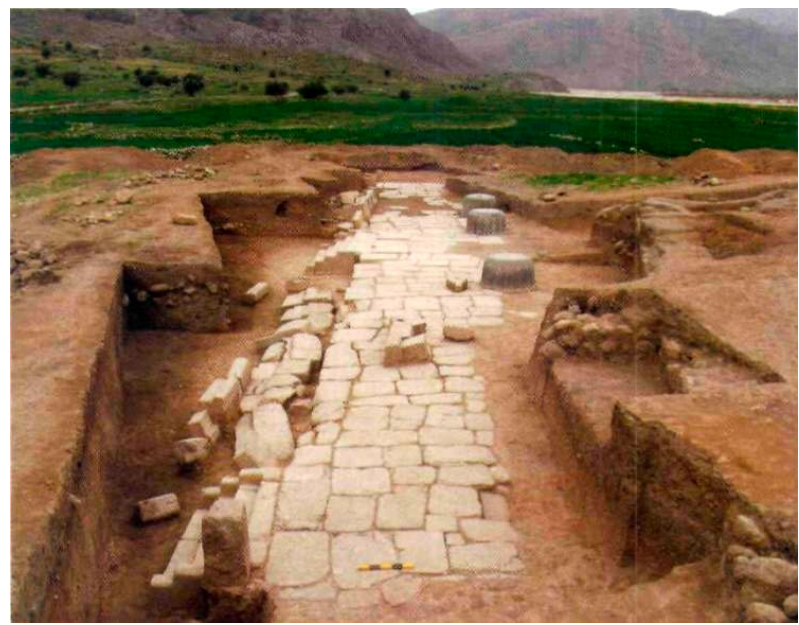

Figura 3: Vista general del pórtico de Qalēh-ye Kalī. D. T. Potts et alii, 2009, 211.

cuatro columnas centrales de gran tamaño estuvieran flanqueadas por otras más pequeñas, tal y como se ha realizado para reconstruir el Palacio S de Pasargadā (Stronach, 1978, fig. 4a). Además, una pequeña columna de forma cuadrangular se encuentra reutilizada en uno de los muros islámicos hallados en el sitio, pudiendo ser el tipo de pequeña columna utilizado en las secciones occidental y oriental del pórtico, aunque esta base es similar a las empleadas en el frataraka de Persépolis, fechadas en un periodo posterior a los aqueménidas, por lo que esa columna podría pertenecer a una estructura completamente diferente (Callieri, 2007, 49-93 y figs. 57-60). Otra posibilidad es que el resto de las columnas no fueran realizadas en piedra, tal y como se ha observado en Persépolis, donde existen columnas de madera recubiertas de yeso. Si las columnas de Qalēh-ye Kalī fueron realizadas en madera, tal situación explicaría la ausencia total de tambores de columna de piedra en las excavaciones (Potts et alii, 2009, 216).

También se halló, al sur de las bases de columna, una enorme zona pavimentada hecha con losas de piedra de forma irregular, no muy bien trabajadas y sin pruebas de alisado, que marcaban probablemente el camino de entrada al interior del edificio, con tres escaleras, dos más pequeñas en las esquinas oriental y occidental del pórtico, y una tercera más grande en el centro, frente a las bases de columna (Potts et alii, 2009, 227-235). En general, los adoquines utilizados alrededor de las escaleras centrales y de las bases de columna son más regulares en tamaño y en forma que los que se encuentran en otras partes de la acera. Además, lajas de piedra más pequeñas entre los adoquines más grandes sugieren, posiblemente, reparaciones del pavimento original. La artesanía relativamente pobre exhibida por estos adoquines, especialmente en comparación con las bases de columna y el nivel de la mano de obra observado en Persépolis y Pasargadā, se podría explicar por el hecho de que Qalēh-ye Kalī es un sitio provincial en el camino real, no un palacio en uno de los centros metropolitanos aqueménidas (Potts et alii, 2009, 217).

Además, es ciertamente posible que, considerando que las bases de columna pudieron haber sido talladas por maestros artesanos en o cerca de Persépolis, utilizando la típica fina piedra caliza de color azúl-grisaceo de Kūh-e Rahmat (Nylander, 1970, 28-29), los adoquines y otros elementos realizados con una piedra caliza mucho más gruesa y de color blanco, pueden haber sido tallados localmente por albañiles menos competentes (Potts et alii, 2009, 217). Sin duda, el descubrimiento de al menos un indefinido merlón, sugiere que los elementos arquitectónicos se están preparando en Qalēh-ye Kalī. En su totalidad la medida del pórtico columnado sería de aproximadamente $31 \mathrm{~m}$ de este a

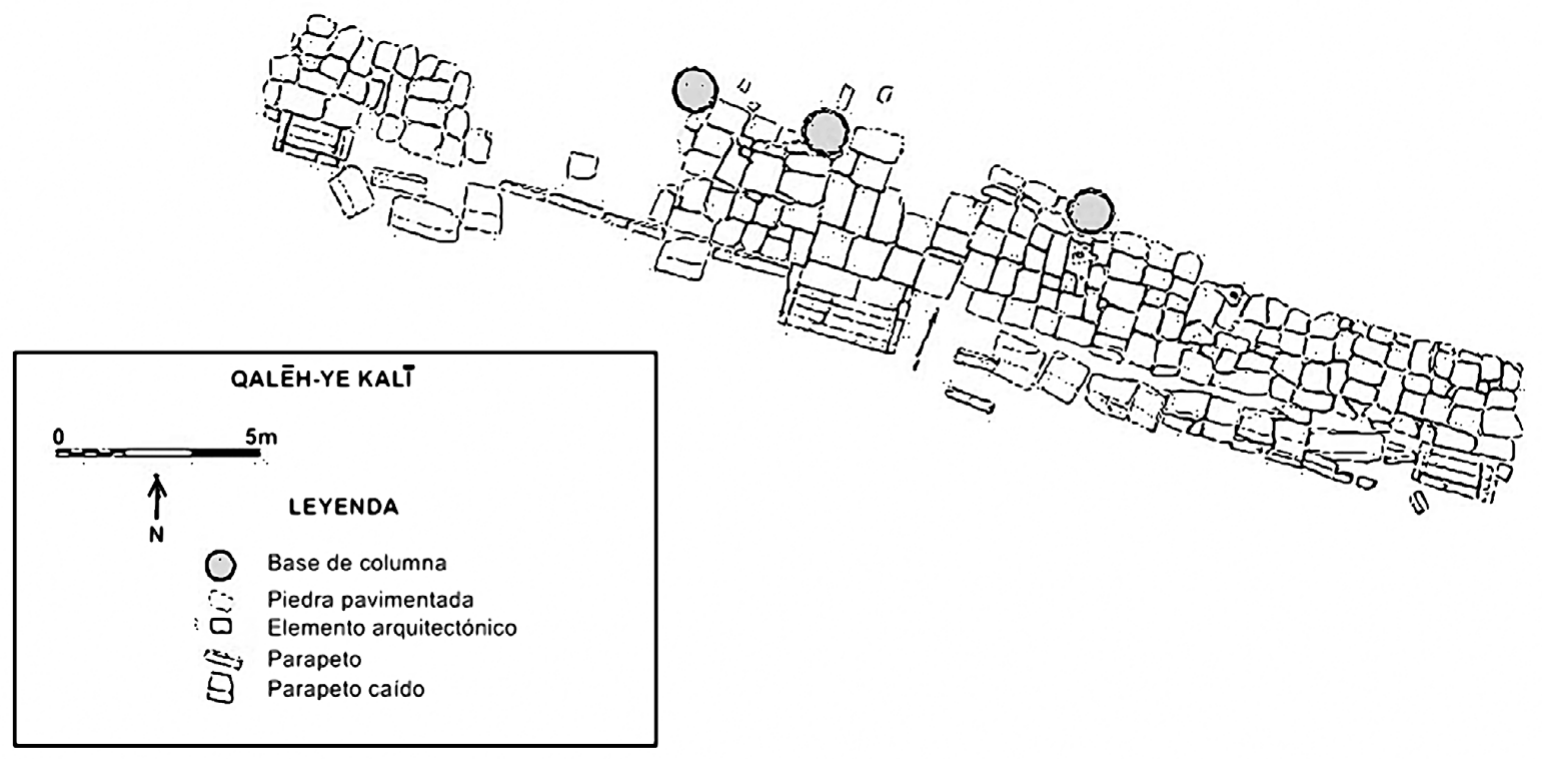

Figura 4: Plano del pabellón de Qalēh-ye Kalī. D. T. Potts et alii, 2009, 258. 
oeste, y de 2,5 a 3,5 m de ancho (Fig. 4) (Potts et alii, 2009, 217). También, en algún momento anterior al colapso de los muros de adobe del edificio relacionados con el pórtico de piedra, se produjo un expolio, en particular de los adoquines situados hacia el extremo occidental (Potts et alii, 2009, 222). Al norte del pórtico, y casi en paralelo con la línea de bases de columnas, se halló la base de una estructura de ladrillos de gran tamaño, así como otras estructuras de piedra y adobe fueron identificadas más al norte, aunque no está claro si estas construcciones están asociadas con la ocupación del sitio (Potts et alii, 2009, 235-238).

Además, dos enormes fragmentos de piedra rectangulares, tal vez uno el resto del dintel de una puerta, y el otro el marco de ésta, fueron descubiertos en un área adyacente a la zona pavimentada (Potts et alii, 2009, 210). También se han encontrado varios fragmentos de recipientes de piedra muy bien pulidos de color blanco (¿mármol?), verde oscuro (¿serpentina?) y rosado (¿mármol travertino?), comparables a los ejemplos conocidos de Persépolis, así como pedazos de cristal inusualmente finos (Potts et alii, 2009, 255 256). Además, la extrema delicadeza del vidrio y la alta calidad de los fragmentos cerámicos en piedra hallados señalan con claridad que son artículos de lujo destinados al uso de individuos pertenecientes a la élite aqueménida, aunque su uso sería meramente periódico. De todas formas también hay que tener en cuenta el hallazgo de una gran cantidad de fragmentos cerámicos muy grandes destinados al almacenamiento y que han sido fechados tanto en la época aqueménida como en la post-aqueménida. Estos fragmentos podrían estar señalando la presencia de un número no despreciable de funcionarios, trabajadores agrícolas locales y tal vez artesanos, que serían residentes en el lugar, probablemente a lo largo del año. La presencia de dicho personal de apoyo en absoluto contradice la llegada periódica de personajes vinculados a la élite aqueménida, donde la opulencia de los objetos sugiere que esta edificación no era una simple estación para el viajero ordinario.

Podría haber sido un almacén real, o incluso un centro de distribución de mensajeros «normales» ubicados en o cerca de Qalēh-ye Kalī, aunque este edificio, con sus enormes bases de columna en forma de campana, así como las comidas y bebidas consumidas en exquisitos vasos de cristal y de piedra, reflejan su asociación a una élite, no al tipo de almacén reflejado tan a menudo en los textos del Archivo de la Fortificación de Persépolis. De todas formas este no parece haber sido el único edificio, puesto que se han hallado otras estructuras al sur de éste, aunque no está claro que se fechen en el periodo aqueménida. Del mismo modo, se han descubierto uno o más edificios al este de Qalēh-ye Kalī, bajo la aldea moderna de Jin-Jin, así como restos de bases de columna en Tol-e Gachgaran, a unos pocos kilómetros al sur, y también en al norte (Boucharlat, 2013, 521). Si este es el caso, se puede estar ante un complejo de edificios, más bien que ante una estructura aislada utilizada para dar cobijo a los viajeros que se desplazaban a lo largo del camino real. Esta posibilidad deberá ser investigada en futuras excavaciones.

\section{Tell Hakavan}

Otra de estas fastuosas construcciones se ha hallado en Farmeshghān (Tell Hakavan o Hakhavan), en el distrito de Kavar, al sur del Fārs ${ }^{5}$. El emplazamiento está situado a unos $90 \mathrm{~km}$ al sur de Šìrāz, en las inmediaciones de la carretera moderna que une Šìnāz con Fīrūzābād. De todas formas es más apropiado decir que era un complejo palaciego con muchos paralelos con las construcciones de Persépolis y Pasargadā. Los estrechos pasillos existentes al aire libre entre los edificios pueden ser comparados a los hallados en Persépolis. Tales corredores se encuentran en Persépolis entre Palacios como la Tachara y el Palacio G, como todavía puede observarse en el yacimiento. Antes de la destrucción de Persépolis otros edificios también tenían estos pasillos al aire libre entre ellos, los existentes entre el Palacio de Hadish y los Palacios H y D. Estos corredores también se encuentran entre la puerta del Tripylon y el Palacio G, y entre la Tachara y la Apadāna. En Persépolis algunos de estos pasillos miden alrededor de un metro de ancho, mientras que los de Hakavan tienen unos $70 \mathrm{~cm}$ de anchura. Estos corredores abiertos entre los edificios parecen haber sido una tradición en la arquitectura aqueménida, teniendo acceso libre a otras unidades sin necesidad de pasar o cruzar a través de espacios interiores, ya que era una manera adecuada para que los funcionarios públicos y los guardias circularan. Hakavan y Persépolis comparten esta característica.

Una diferencia entre Hakavan y Persépolis es la dimensión de los edificios. En Persépolis los edificios son mucho más grandes que aquellos que se encuentran en Hakavan. La estructura más grande hallada en Hakavan es su estructura central que mide 9,40 x 8,32 m (Razmjou, 2005, 307). Las estructuras circundantes son incluso más pequeñas y menores que las que se encuentran en Persépolis. Un número de decoraciones en roseta encontradas en el sitio son comparables a las de Persépolis y Susa. Además algunos de los fragmentos pertenecientes a columnas y relieves son del mismo estilo y calidad que los de Persépolis.

Desde el punto de vista arquitectónico, la parte de la voluta de las columnas nos habla de la columna por sí misma. En uno de los fragmentos se observa que la roseta está partida a la mitad. La longitud desde el exterior del fragmento al borde de la desaparecida flor es de aproximadamente $6 \mathrm{~cm}$. En comparación, una parte similar de una columna del pórtico sur del Palacio de

5. Para más información sobre las excavaciones en Tell Hakavan véase Razmjou, 2005, 293-312. 
la Apadāna en Persépolis es de $5,3 \mathrm{~cm}$, una diferencia no significativa. Esto demuestra que el tamaño de la columna era del tamaño de una de las columnas que componían el Pórtico sur de la Apadāna. Esto sugiere una altura aproximada de $5 \mathrm{~m}$ para las columnas del Palacio de Farmeshghān. Una comparación similar puede encontrarse en el trabajo de Krefter, que propone una medición de $1,54 \mathrm{~cm}$ para la parte superior de la cornisa del pórtico sur de la Apadāna (Krefter, 1971, 85). Por lo tanto, se puede sugerir una altura total para el Palacio de Farmeshghān de aproximadamente $7 \mathrm{~m}$ de altura. Para semejante elevación, el grosor de las paredes debe de haber sido de alrededor de $1,20 \mathrm{~cm}$ o menos (Razmjou, 2005, 309). Teniendo en cuenta los diferentes tipos de fragmentos, se ha sugerido que existieron al menos dos o tres habitaciones columnadas en Hakavan, que podrían aumentar la importancia de este complejo, aunque hay que tener en cuenta que no eran tan grandes como las salas de los palacios de Persépolis.

\section{FīrūZĀBĀD, LĀMERd Y TALL-E ZOHAK}

Otra de estas importantes construcciones podría encontrarse en Fīrūzābād, localidad emplazada a unos $100 \mathrm{~km}$ al sur de Šìrāz. A unos $300 \mathrm{~m}$ del centro de la ciudad sasánida e islámica se halló un tambor de columna acanalado en piedra blanca con un diámetro de $80 \mathrm{~cm}$ y de aspecto aqueménida (Mostafavi, 1967, 3008). Se observó también que existían otros restos pertenecientes al periodo aqueménida que habían sido reutilizados en torno al monumento central del periodo sasánida e islámico (Huff, 1999), quizás de un antiguo emplazamiento situado en las proximidades, quizás de Farmeshghān, o en la propia Fīrūzābād.

Siguiendo hacia el sur, en Lāmerd, una prospección emprendida en la región meridional de Irán dio lugar al descubrimiento de elementos arquitectónicos asombrosos que pueden estar también en relación con uno de estos "pabellones» ${ }^{6}$. Se hallaron fragmentos de capiteles en volutas, prótomos de animales inspirados claramente en el arte aqueménida, aunque de factura bastante tosca, que, como en el caso de Tall-e Zohak que veremos a continuación, podrían fecharse en un periodo post-aqueménida, aunque no puede rechazarse que fueran el resultado de un arte provincial (Boucharlat, 2005, 235).

En Tall-e Zohak, localizada en el valle de Fasā, a $3 \mathrm{~km}$ al sur de la moderna ciudad de Fasā, esto es, a $130 \mathrm{~km}$ al sureste de Šîrāz, las prospecciones realizadas por A. Stein desvelaron una cabeza femenina en mármol de inspiración helenística, fechada entre los siglos III-II a.C., y una base de columna redonda de tipo aqueménida (Stein, 1936, 137-142). También

6. Sobre los hallazgos en Lāmerd, ver Asgari Chaverdi, 2001, 66-71; 2002, 277-278. se hallaron sobre el lugar restos cerámicos de barniz marrón-rojizo, fechados en el periodo aqueménida, en la zona de la columna y sobre un gran Tell, situado en la parte noreste del lugar, que está constituido de capas prehistóricas en la base y en su parte superior por una plataforma de ladrillos de barro que se eleva alrededor de los $8 \mathrm{~m}$ de altura. Sobre las cuestas de este Tell se hallaron también restos fechados en el periodo aqueménida. Mostafavi informó del descubrimiento de una base de columna de piedra negra, así como, cerca de allí, de varias piedras circulares semejantes a las piedras y bases de columna de Persépolis y Pasargadā, reutilizadas en una construcción del siglo XV (Mostafavi, 1978, 241). Más recientemente, R. Pohanka reexaminó cuidadosamente el lugar, descubriendo más bases fragmentarias de columnas (Pohanka, 1987, 20-28). Una de ellas es similar a la del primer descubrimiento, campaniforme, acanalada y decorada con ovados en la cumbre. No se trata de un fragmento de la misma base, puesto que las otras tienen un perfil convexo o incluso una forma cilíndrica; son probablemente imitaciones post-aqueménidas, aunque la hipótesis de un arte provincial no puede excluirse, puesto que parece no haber duda de que era un centro aqueménida de relativa importancia (Boucharlat, 2005, 234).

\section{Deh Bozan}

Otra estación de características palaciegas ha sido localizada en la aldea de Deh Bozan, localidad emplazada a $11 \mathrm{~km}$ al sur de la moderna ciudad de Asadabad, y a $3 \mathrm{~km}$ al este de la carretera que une las localidades de Asadabad y Kirmānšāh, al noroeste de Irán ${ }^{7}$. En el sitio se han hallado fragmentos de cinco toros ${ }^{8} \mathrm{y}$ tres basas de columnas acampanadas, realizados sobre piedra calcárea negra pulida y que no presentan decoración (Mousavi, 1989, 135-136). Los ejes de las columnas eran probablemente de madera, y estaban fijados sobre las basas y sus toros. Uno de los toros está dañado gravemente, aunque el resto está relativamente bien conservado. Las basas tienen un diámetro de $90 \mathrm{~cm}$ y una altura de $40 \mathrm{~cm}$, mientras que los toros tienen un diámetro de $64 \mathrm{~cm}$ y una altura de $15 \mathrm{~cm}$ (Mousavi, 1989, 136). Es probable que el sitio contara con seis columnas, con una probable azotea de madera sobre ellas, lo que vendría a confirmar la existencia de una estación palaciega en Deh-Bozan (Mousavi, 1989, 136). La forma acampanada de las basas nos ayuda a fecharlas durante el período aqueménida, aunque la ausencia de decoración es un problema para dar una fecha y una comparación exacta (Mousavi, 1989, 138).

7. Para más información sobre los hallazgos de Deh Bozan véase Huff, 1988, 285-295; Mousavi, 1989, 135-138.

8. El toro es una moldura convexa grande, especialmente en la base de una columna clásica. 


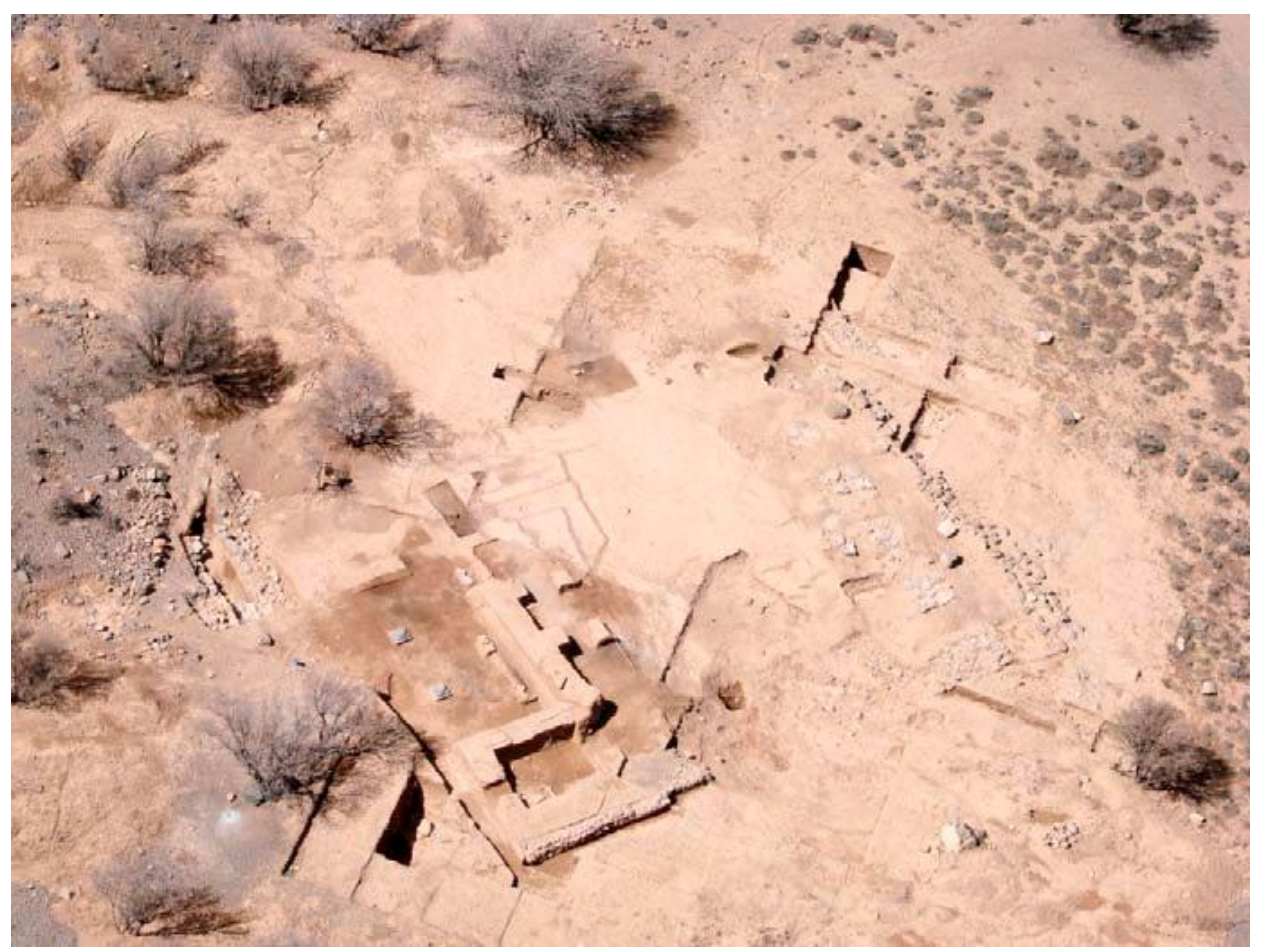

Figura 5: Vista aérea del Sitio TB 34, en Tang-e Bulaghi. Atai y Boucharlat, 2009, 10.

\section{TANG-E BULAGHI}

En Tang-e Bulaghi se han hallado los restos de un pequeño «pabellón» (TB 34), donde se incluyen una base en forma de campana, dos plintos cuadrangulares todavía in situ en un pórtico, y numerosos restos fechados en el periodo aqueménida y post-aqueménida que evidencian con claridad que era un edificio perteneciente a la élite (Fig. 5) ${ }^{9}$. El «pabellón» está situado en el margen izquierdo del río Pulvār, al pie de un acantilado de $180 \mathrm{~m}$ de altura y emplazado a $6 \mathrm{~km}$ al sur de la tumba de Ciro II. El edificio tiene vistas sobre el río y está situado sobre una terraza natural de forma rectangular, presentando ésta unas dimensiones de 120 x $70 \mathrm{~m}$. El plano del edificio es casi cuadrado, con dos pórticos en oposición de diferentes tamaños (Fig. 6). El edificio tenía unas medidas de 24,60 x 19 m (Atai y Boucharlat, 2009, 9). El espacio interno no presenta una única gran sala interior como los edificios A y B de Pasargadā, sino que contiene una serie de tres salas paralelas en la parte trasera con una estructura en forma de L, probablemente correspondiente a una escalera, al sur. Entre el pórtico frontal y las tres habitaciones, además de una pequeña sala en la esquina occidental, parece haber un único espacio, que es demasiado amplio para no haber estado columnado, aunque ningún rastro de bases de columnas se ha hallado en asociación a este espacio (Atai y Boucharlat, 2009, 10).

9. Sobre las excavaciones en el sitio TB34 de Tang-e Bulaghi véase Atai y Boucharlat, 2009, 1-33.
Las bases de las columnas eran de tres tipos. En primer lugar, hubo bicolores (de acuerdo con los fragmentos encontrados). En segundo lugar, zócalos cuadrados en el pórtico frontal; su altura es desconocida, y el lado habría medido $65 \mathrm{~cm}$ en función del tamaño del bloque que descansa sobre los cimientos. En el pórtico trasero dos zócalos escalonados de piedra caliza gris, de $65 \times 65 \times 22 \mathrm{~cm}$, con el toro, formaba una base de $30,5 \mathrm{~cm}$ de altura. Y en tercer lugar una única base acampanada de piedra caliza de color gris oscuro (de $31 \mathrm{~cm}$ de altura), decorada con hojas estilizadas (Atai y Boucharlat, 2009, 13). El nivel del piso del pabellón, en los pórticos y en las habitaciones interiores, se encontraba al nivel de la superficie natural, aunque en otros lugares era más alto, alcanzando una altura de $1,40 \mathrm{~m}$ en la parte frontal del pórtico occidental. En consecuencia, tendría que haber existido una escalera en algún lugar, muy probablemente en el lado occidental, aunque no se han encontrado sus restos. Partes de la azotea son señaladas por la presencia de una viga de madera situada a lo largo de la pared trasera del pórtico oriental; además presenta una longitud de $3,40 \mathrm{~m}$, lo que corresponde a la distancia entre las dos bases de columna o entre las bases y las paredes laterales (Atai y Boucharlat, 2009, 14-15). Además se han hallado numerosos restos cerámicos, como cuencos carenados, tazones con asas horizontales, tarros de almacenamiento, etc. (Atai y Boucharlat, 2009, 18-19).

Dada la precaria conservación del edificio, la reconstrucción que se ha realizado es necesariamente especulativa (Atai y Boucharlat, 2009, 20-21). El aspecto externo del pabellón difiere de los edificios de Pasargadā, que presentaban amplios espacios abiertos 
Tang-i Bulaghi. Sitio TB 34

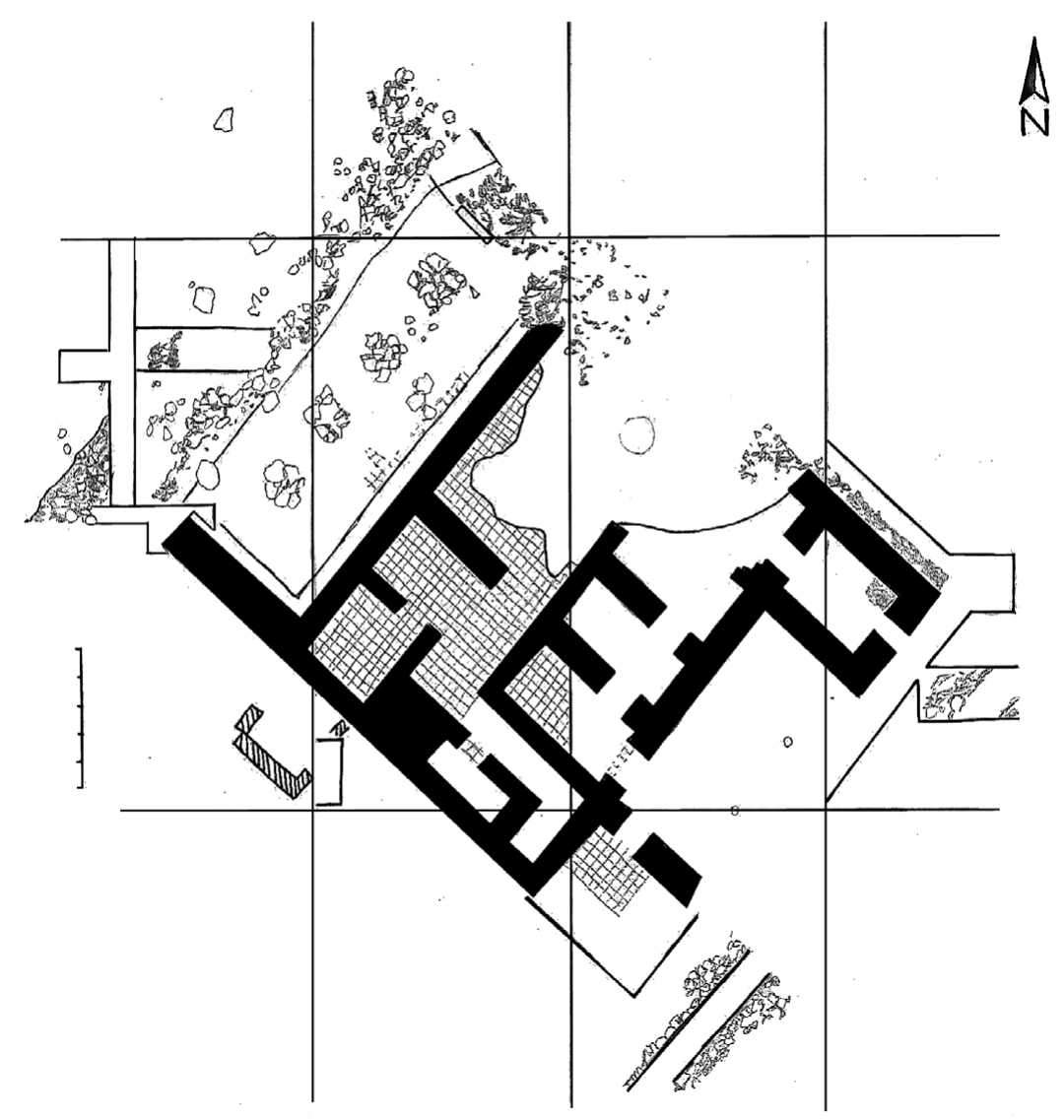

Figura 6: Plano del sitio TB 34, en Tang-e Bulaghi. Atai y Boucharlat, 2009, 8.

con pórticos en sus cuatro lados (Palacio S, Pabellones A y B), o con dos pórticos largos y rebajes en los lados cortos (Palacio P). Se puede sugerir que se accedía al recinto por una escalera corta, de 1 a $1,50 \mathrm{~m}$ de altura, en la zona destruida en la parte norte del pórtico frontal (Fig. 7). El acceso al pórtico trasero no habría requerido una escalera, ya que estaba situado al nivel de la superficie. Sin embargo, la existencia de un foso, que seguramente no estaba cubierto, habría exigido la presencia de un puente para cruzarlo (Atai y Boucharlat, 2009, 20). El diseño interior del pabellón es bastante inusual para la arquitectura aqueménida: en lugar de una sola sala, como en los edificios de Pasargadā, o una sala principal, como en muchos edificios de Persépolis, este pabellón es una estructura de múltiples habitaciones. El enigmático espacio alargado situado en la parte trasera del pórtico noroeste es de $6 \mathrm{~m}$ de ancho, por lo que no podría haber sido techado sin una fila de pilares intermedios o tabiques. Dado que no se ha encontrado ningún rastro de una fundación en el piso de ladrillos de barro, como ocurre en el caso de las bases de los dos pórticos, se ha sugerido que existían tabiques, aunque han desaparecido completamente (Atai y Boucharlat, 2009, 21).

En cuanto a la altura del edificio, un cálculo basado en las proporciones del diámetro o del lado de las bases de columna, la proporción de los pórticos de los ejemplos conocidos en Pasargadā y Persépolis, y el espesor de las bases, ha llevado a la reconstrucción de las columnas y los muros a una altura mínima de 6 $\mathrm{m}$, aunque probablemente se elevaban a mayor altura (Atai y Boucharlat, 2009, 21). Dado que no hay ningún fragmento de tambores de columna de piedra, la existencia de pilares de madera es una posibilidad, como en la mayoría de los edificios aqueménidas. Tanto por motivos arquitectónicos como por la localización del «pabellón», se ha atribuido su construcción al reinado de Darío, puesto que también se conoce la actividad arquitectónica de este monarca, tanto en Tall-e Takht como en el palacio $\mathrm{P}$ y posiblemente en el Pabellón $\mathrm{B}$ de Pasargadā (Atai y Boucharlat, 2009, 22).

Además, también se ha observado la presencia de una serie de canales procedentes de la orilla oriental del cercano Pulvār que habrían abastecido a esta edificación (Atai y Boucharlat, 2009, 23-30). Se conoce la existencia, en ambas orillas del río, de 2 canales, donde el oriental se extendía por más de $10 \mathrm{~km}$, que habrían servido para irrigar la terraza aluvial del Tang-e Bulaghi. Así, el "pabellón», situado en un entorno agradable, cerca del río, no lejos de Pasargadā, puede haber actuado como estación para el monarca o para los altos dignatarios de la corte aqueménida (como veremos, existía otro edificio en Tang-e Bulaghi más modesto, destinado al resto de viajeros), puesto que 


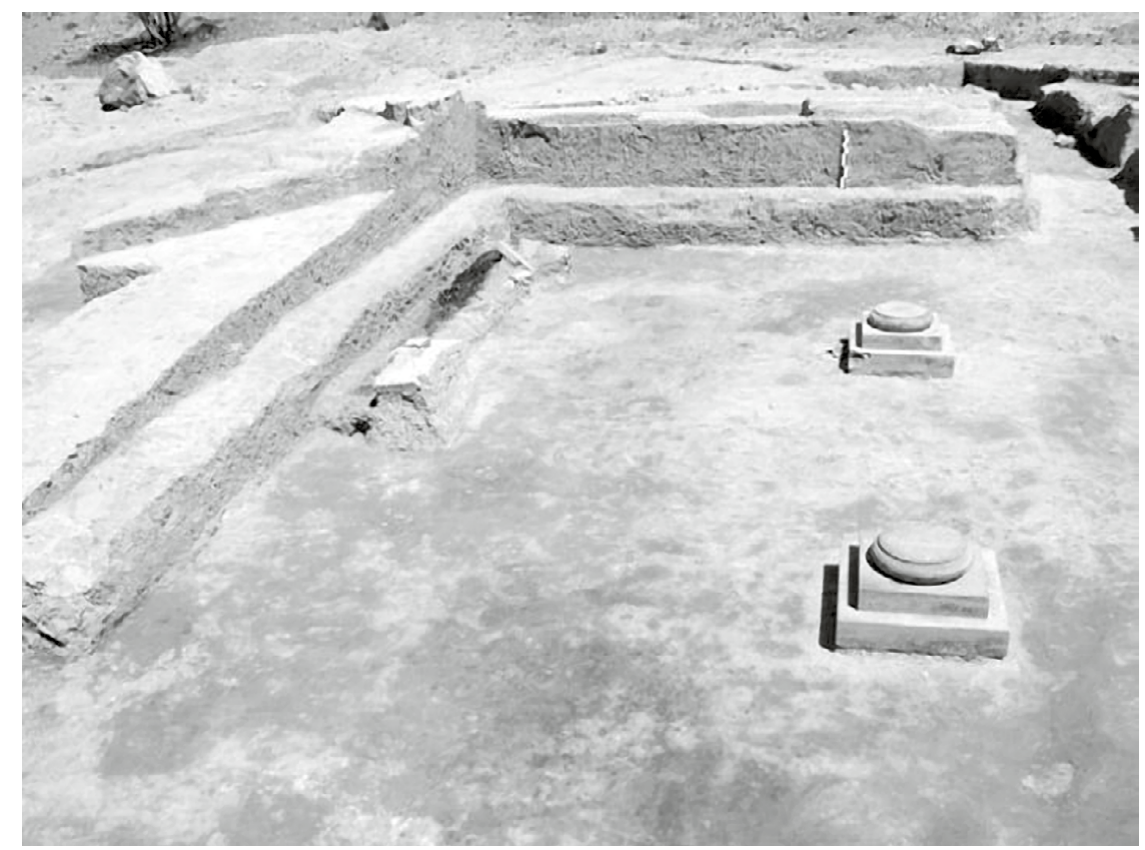

Figura 7: Pórtico frontal del sitio TB 34, en Tang-e Bulaghi. Atai y Boucharlat, 2009, 15.

ofrecía alojamiento y habitaciones adecuadas para el almacenamiento de mercancías y objetos, y dada la presencia también de un camino esculpido en la roca en esta misma región refuerza la idea de que pueda tratarse de una estación palaciega.

\section{BORĀZĞ̄̄AN Y MALYĀN}

En Borāzğān se ha descubierto también lo que parece ser un «pabellón» a $1 \mathrm{~km}$ al sur de esta ciudad, a aproximadamente $50 \mathrm{~km}$ de la costa del Golfo Pérsico (Sarfaraz 1969; Boardman 2000, 65-66). Se descubrieron 12 bases de columna, en dos hileras de seis columnas. Presentan éstas zócalos cuadrados hechos de dos tipos diferentes de piedra, una negra y otra blanca, como en el palacio S de Pasargadā. Por este motivo el edificio se ha fechado la época de Ciro. Según S. Ramjou, el lugar implicaría varias construcciones, quizás cinco (Razmjou, 2005, 310), lo que invitaría a revisar el calificativo de «pabellón» que se ha utilizado para denominar este descubrimiento.

En la aldea de Malyān, en Toll-e Bayzāy-e Fārs, en el moderno distrito de Baydā, a aproximadamente 50 $\mathrm{km}$ al oeste de Persépolis y a $43 \mathrm{~km}$ al norte de Šīrāz, se identificó la antigua Anšan. Durante un largo período dio su nombre a esta región y a veces incluso a toda la parte meridional de Irán. Soberanos como Ciro II, así como sus antecesores, declararon ser reyes de esta región, aunque en época de Darío I no poseía el mismo fasto que en periodos precedentes, tanto a nivel simbólico como arqueológico, puesto que el periodo aqueménida no se ha certificado hasta el descubrimiento muy reciente de bases de columna que pertenecían sin duda a un edificio aristocrático, posiblemente un «pabellón» (Summer, 1986, 11) ${ }^{10}$. Pero la superficie de esta construcción se define mal y su función se desconoce completamente, por lo que más estudios son necesarios para poder sugerir más sobre esta instalación.

\section{INSTALACIONES DE CARACTERÍSTICAS MODESTAS}

Conocemos otras estructuras más modestas que podían estar señalando la presencia de una estación emplazada sobre el camino real aqueménida. Por ejemplo, en el curso de la prospección de unos $43 \mathrm{~km}$ entre Naqš-e Rustam y Madakeh de una porción de la ruta que unía Persépolis con Susa, a $8 \mathrm{~km}$ al noroeste de Naqšs-e Rustam y a 4 km al sureste de Germabad, se han hallado, sobre una loma, los restos de un edificio de forma rectangular, de $30 \mathrm{~m}$ de longitud, que contaba con una serie de compartimentos (Fig. 8). Los restos descubiertos muestran que el sitio fue ocupado durante varios periodos históricos, aunque su planta más antigua puede fecharse en el periodo aqueménida. La situación del hallazgo ha provocado que los restos se hayan atribuido a los de una estación situada sobre el camino real (Kleiss, 1981, 46).

También, al noroeste de estos restos, y siguiendo el curso del mismo antiguo camino, en Ramjed, a $5 \mathrm{~km}$ al oeste de Madakeh, Kleiss informó de lo que podría ser una segunda estación aqueménida (Kleiss, 1981, 4850). El sitio consiste en un edificio de piedra $(40$ x 30 $\mathrm{m}$ de longitud), compuesto por cinco habitaciones, y

10. Para más información sobre estas bases de columna ver K. Abdi, 2001, 92-93. 


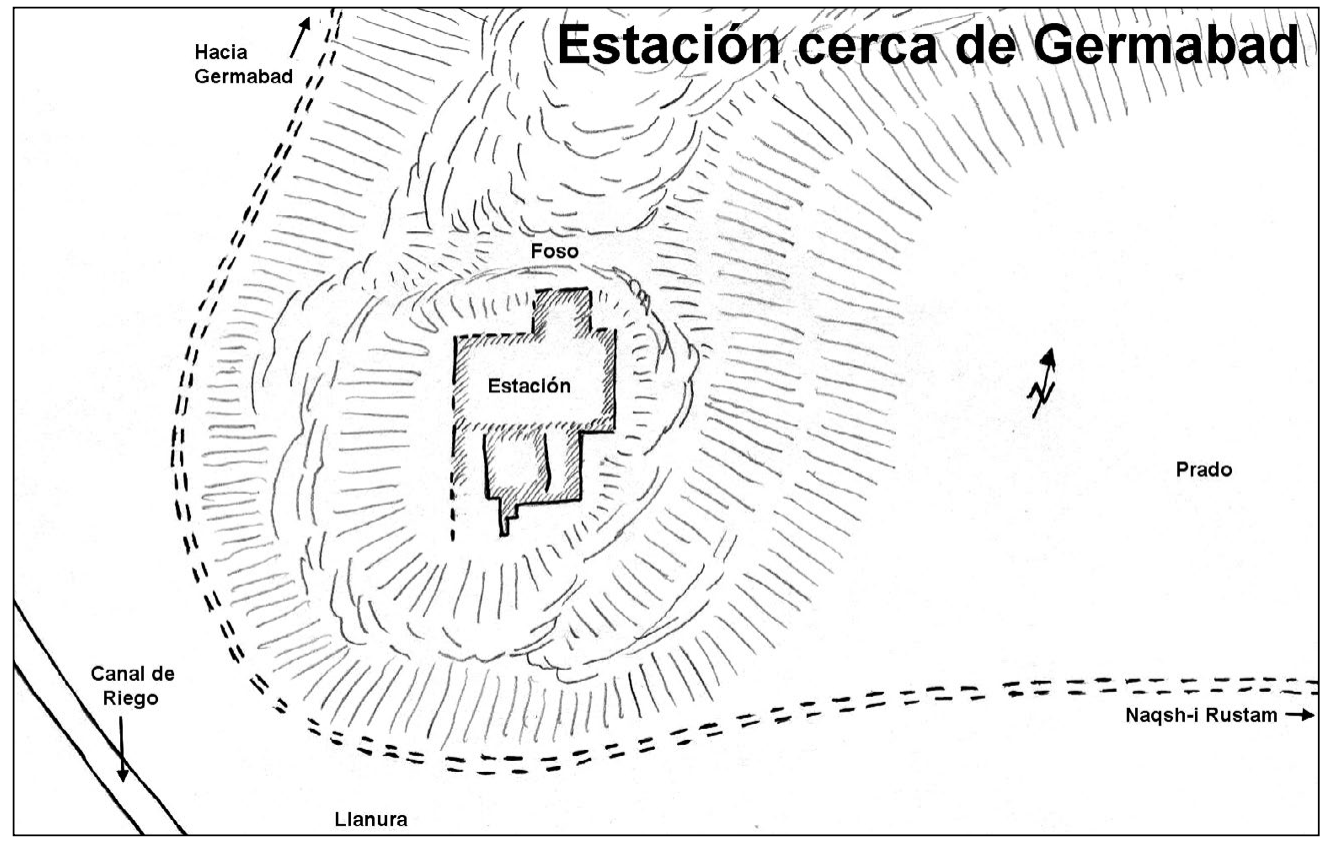

Figura 8: Estación en las inmediaciones de Germabad. Dibujo de W. Kleiss, 1981, 46.

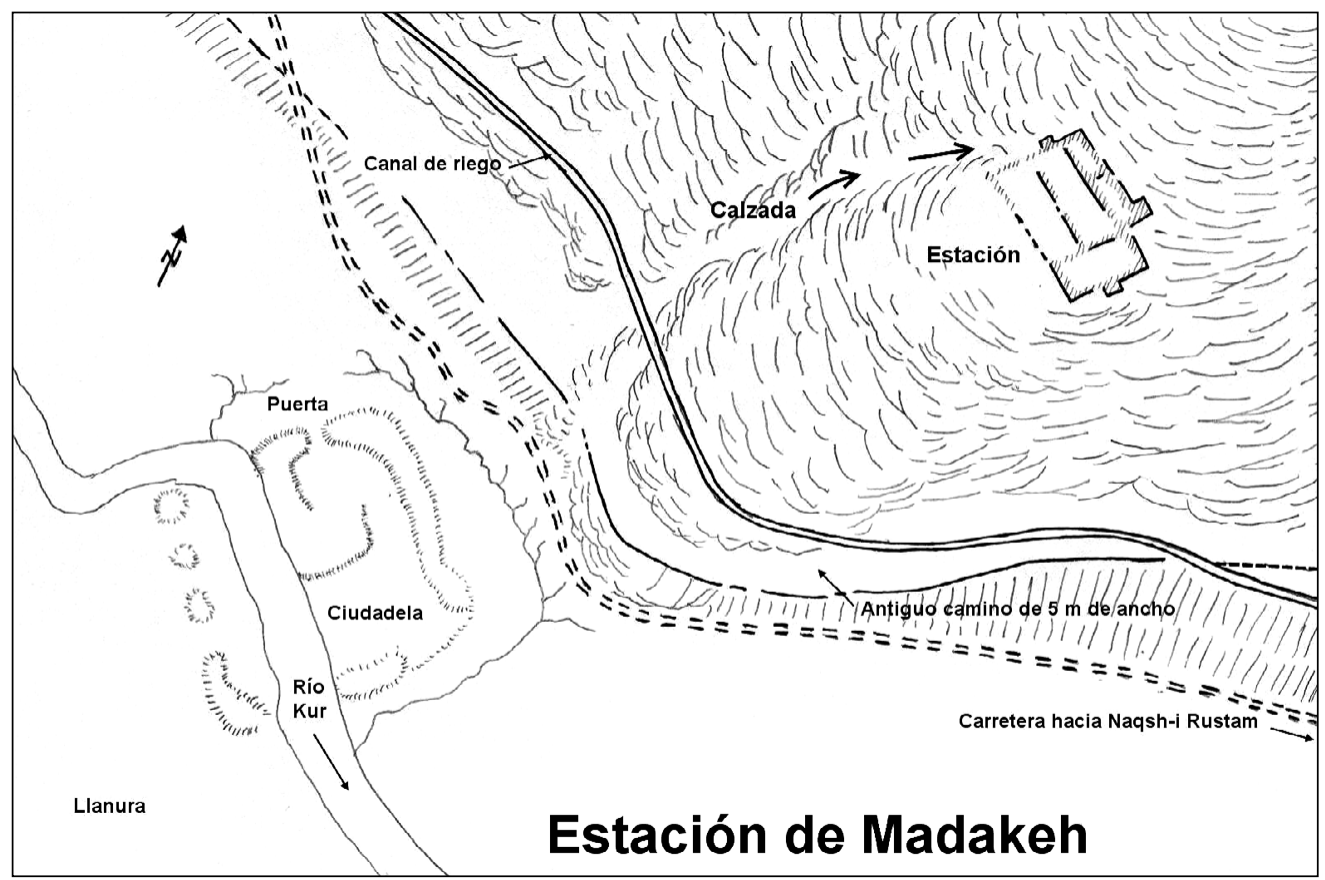

Figura 9: Estación en las inmediaciones de Madakeh. Dibujo de W. Kleiss, 1981, 49.

dispuesto sobre una elevación de la llanura, igual que los restos hallados en la estación próxima a Germabad (Fig. 9). El promontorio sobre el que descansa el edificio sobresale a menos de $150 \mathrm{~m}$ del canal del Río Kur, donde el talud es erosionado sutilmente por la pequeña corriente que fluye en el río. Un canal moderno de irrigación está cortando el lecho de la roca madre sobre el promontorio, donde debajo de este canal hay una muesca con un piso de $5 \mathrm{~m}$ de anchura que fue cortado de par en par en la roca. Kleiss interpretó esta característica como un corte en la roca provocado por el camino que iba a lo largo del Río Kur, es decir, como parte del camino real aqueménida. Además, en el sitio, se han hallado restos cerámicos, fechados durante todo el I milenio a.C., lo que denota una ocupación prolongada del lugar.

En Tang-e Bulaghi, en las proximidades de Pasargadā, se ha hallado otro de estos edificios. Una expedición arqueológica polaco-iraní realizó una excavación de rescate en el sitio 64 de Tang-e Bulaghi, fechado en época sasánida, donde se hallaron restos cerámicos pertenecientes al periodo aqueménida, tanto 


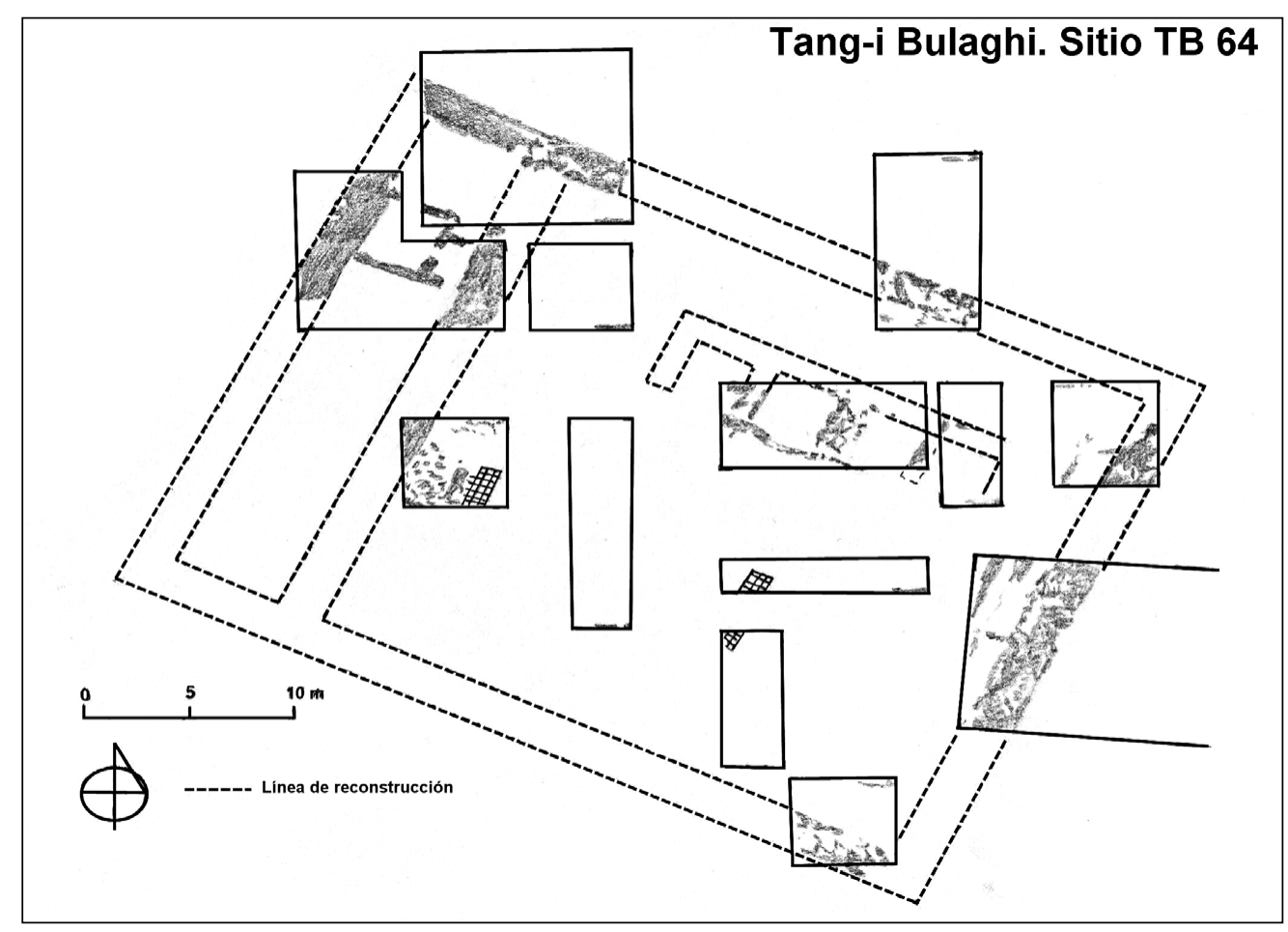

Figura 10: Tang-e Bulaghi. Sitio TB 64. Asadi y Kaim, 2009, 4.

en la superficie como en los estratos inferiores del edificio (Asadi y Kaim, 2009, 1). Se reconstruyó, además, la línea de un muro que rodeaba un área rectangular de aproximadamente $40 \times 30 \mathrm{~m}$. Este muro tiene unos 2 $\mathrm{m}$ de espesor, estando compuesto por grandes piedras toscamente trabajadas, colocadas en dos hileras. Por encima, una capa de piedras más pequeñas y una capa de arcilla de 5 a $8 \mathrm{~cm}$ de grosor fueron colocadas con el fin de producir una especie de superficie. También se detectó la presencia de varias habitaciones que bordeaban el muro oriental. Los restos de algunas estructuras también fueron desenterrados en la parte norte de la zona rodeada por estas paredes (Fig. 10).

Aunque las bases de los muros están construidas por dos hileras de rocas y piedras más pequeñas, parece posible reconstruir aquí una fila de por lo menos cuatro habitaciones cuadradas $(3,30 \times 3,30 \mathrm{~m})$ con paredes en tres de sus lados y una abertura sobre la cuarta (Asadi y Kaim, 2009, 8). Una capa compacta, de unos $10 \mathrm{~cm}$ de espesor, formada por pequeñas piedras mezcladas con barro, sirvió probablemente como un pavimento de protección para los usuarios en los días de lluvia, mientras que el calor y la preparación de la comida parecen haber sido asegurados por medio de fogones, cuyas huellas se detectaron en el suelo, y por un sub-hogar rectangular ubicado en la plataforma baja $(0,55 \times 1,35 \mathrm{~m})$, construido con ladrillos de barro $(33 \times 33 \times 10 \mathrm{~cm})$ contra una de las paredes (Asadi y Kaim, 2009, 8). Los restos de otra estructura fueron desenterrados en la parte occidental de la zona, con un muro de ladrillos de barro, de 1,05 $\mathrm{m}$ de ancho, compuesto por tres hileras de ladrillos $(33 \times 33 \times 10$ $\mathrm{cm})$ paralelas a la enorme pared de $3 \mathrm{~m}$ situada al este (Asadi y Kaim, 2009, 9).

De todas formas no existen pruebas suficientes para la reconstrucción de un plano de toda la estructura construida aquí. En cualquier caso, la función de almacenamiento de la estructura es segura por los numerosos restos cerámicos hallados (Asadi y Kaim, 2009, 10). La interpretación de toda la estructura es mucho más difícil, aunque hay una clara semejanza con otras construcciones aqueménidas, como las de de Madakeh y Germabad. En cualquier caso, el esfuerzo necesario para construir este edificio y la presencia de cerámicas especiales sugieren una construcción ordenada por la administración real. La naturaleza y la función de las salas de la parte norte tienen un papel crucial en la interpretación de la estructura. Como las habitaciones están dispuestas en una fila sin comunicación interna y están abiertas a un lado, no pueden haber sido utilizadas para vivir permanentemente o para el almacenamiento. Sin embargo, los hogares, el sub-hogar rectangular, así como la gran cantidad de fragmentos de cerámica sugieren que las habitaciones estaban, al menos, temporalmente habitadas. Tampoco hay duda de que los macizos muros desempeñaron un papel defensivo.

Por ello, se puede proponer como hipótesis, que la función de esta estructura era la de servir como estación real. Esta teoría puede ser confirmada por las excavaciones realizadas en Ramjed, donde, como acabamos de ver, un edificio de piedra de cinco habitaciones, de unos 40 × $30 \mathrm{~m}$ de diámetro, fue descubierto. El tamaño y la disposición general de ambas estructuras, 
pone de manifiesto que son claramente similares, lo que hace que la identificación de la construcción de Tang-e Bulaghi como una estación sea más plausible, además del hecho de que se encontraba sobre el camino real que unía Persépolis con Pasargadā.

\section{CONCLUSIÓN}

Como se ha indicado las estaciones emplazadas sobre el camino real aqueménida podían variar en su forma, dimensiones y en su suntuosidad, aunque con los datos disponibles es imposible dilucidar como eran estas instalaciones en su conjunto, pues los escasos ejemplos disponibles provienen en su mayor parte, salvo el caso de Deh Bozan, del corazón del imperio. Pudieron haberse construido instalaciones lujosas en determinados lugares, sobre todo en aquellas zonas transitadas habitualmente por el monarca aqueménida (como por ejemplo Jin-Jin. Tang-e Bulaghi, Deh Bozan). De todas formas, hay que tener en cuenta, que todos estos edificios suntuosos (Jin-Jin, Farmeshghān, Fīrūzābād, Lāmerd, Tall-e Zohak, Deh-Bozan, Tang-e Bulaghi, Borāzğān y Tell Malyān), generalmente conocidos como «pabellones» han dado lugar a diferentes interpretaciones. ¿Qué representaban este puñado de construcciones alejadas de las residencias reales? En ausencia de respuesta arqueológica, se pueden emitir tres hipótesis: residencias reales, residencias de gobernadores locales o de altos dignatarios de la corte y estaciones reales emplazadas sobre el camino real. Todas estas hipótesis plantean la cuestión de la organización de la élite persa: si son lugares reales, se recordará que, por oposición a Persépolis y a su región, los monumentos del Fārs meridional (Farmeshghān, Fīrūzābād, Borāzğān) se sitúan en regiones que son agradables para vivir durante el invierno. No habría por ello necesidad de situarlos sobre un supuesto «camino real».

Algunos «pabellones», ciertamente, no están emplazados sobre el camino que conectaba dos de las residencias reales aqueménidas más importantes, Susa y Persépolis, como Farmeshghān, al sur de Šīrāz, o Borāzğān, cerca de Būšehr, aunque estás podrían haberse situado sobre caminos en un principio secundarios. Si son residencias de gobernadores o de persas de alto estatus, serían interesantes testigos de la organización político-económica del imperio. Estas construcciones serían el lugar de residencia de la autoridad local, nombrada por el rey, o el centro de una gran explotación dada o confiada por el rey a altos dignatarios de la corte para el desarrollo de las tierras. Está claro que los elementos para una respuesta se encuentran en el estudio intensivo y sobre todo extensivo de estos sitios, es decir, más allá de la parte prestigiosa de la construcción, esto es, la sala columnada, buscando el plano completo del establecimiento y construcciones adjuntas, y, más allá, reconociendo el terreno del que esta residencia podría encargarse.
Otra hipótesis, para algunas de estas construcciones, es decir, las que han sido fechadas en un periodo postaqueménida, y que habrían ejercido la misma función que la propuesta arriba, o por el contrario, señalarían la autonomía de un jefe local después del hundimiento del poder central, como podría ilustrarlo la construcción de Lāmerd en el Fārs meridional, si realmente es de este periodo. La hipótesis de los príncipes independientes parece poco plausible en el siglo que sigue a la caída del imperio aqueménida, durante el cual nada hace indicar actualmente que el poder seléucida haya abandonado el control de estas regiones. En cambio, es posible que esto se produjera después del año 250 a.C., cuando el Fārs escapó del poder de esta dinastía helenística. Como ocurre en Asia Central, es probable que la arquitectura con columnas o postes sobre zócalos cuadrados de tipo aquemenizante haya estado de moda en el periodo helenístico, o incluso en una época posterior.

Esta serie de vestigios debería constituir un programa de investigación interesante para conocer mejor la organización del imperio en las regiones centrales. Además, si estas construcciones están vinculadas a una explotación de las tierras circundantes, constituirían ejemplos interesantes del desarrollo de una tierra que debía estar basada en una óptima gestión del agua. De todas formas, tampoco se puede descartar su existencia como estaciones palaciegas emplazadas sobre el camino real: Farmeshghān, Fīrūzābād y Borāzğān podrían encontrarse sobre dos rutas que se dirigían a las costas del Golfo Pérsico, mientras que las construcciones de Jin-Jin, en el camino que unía Susa con Persépolis, de Tang-e Bulaghi, en la vía que unía Persépolis con Pasargadā, y Deh-Bozan, en el itinerario que se dirigía hasta Ecbatana encajarían perfectamente con esta interpretación.

Además, sabemos que los monarcas aqueménidas estacionaron, durante sus viajes entre las diferentes residencias reales (Babilonia, Ecbatana, Pasargadā, Persépolis y Susa), en una serie de lugares que contaban con una instalación denominada en los textos del Archivo de la Fortificación de Persépolis como partetaš $^{11}$. Alrededor de 40 textos de este archivo mencionan este término ${ }^{12}$. El vocablo es probablemen-

11. Estos lugares son: Akkuban (PF-NN 1455), Appištapdan (PFa 33), Kabaš (PF 146), Nupištaš (PF 146-148; PF-NN $85 ; 817 ; 989 ; 1156 ; 1505 ; 2141 ; 2445)$ y Tikranuš (PFa 33). Puesto que la lista de las plantaciones y la lista de lugares visitados por el rey son necesariamente incompletas, estos cinco casos, probablemente, representan sólo la punta del iceberg.

12. Aparecen con mayor frecuencia en textos de la serie $\mathrm{C} 1$, identificados como recepción de impuestos por Koch, 1980: PF 144 (Matannan = Madana), 145 (Barašba), 146-148 (Nupištaš), 149 (Aptudaraš), 150-151 (Šaurakkaš), 152 (Mutrizaš), 153 (Kutkuš), 154 (Šaurakkaš), 155 (Hapruma), 156 (Kutkuš), 157 (Tamukkan y Kabaš), 158 (Mišdukba), PF-NN 85 (Nupištaš), 222 (Murkaziya), 619 (Kandukka), 813 (Upirizza), 817 (Nupištaš), 989 (Nupištaš), 1156 
te una representación elamita del término en antiguo persa *pari-daida - o paridaeza (Avesta: atestiguado en Videvdad 3.18), «lo que está más allá o detrás de la pared» (Kent, 1953, 195; Lecoq, 1990, 209-211). Su forma meda *paridaiza- («rodeado de paredes») fue tomada por los griegos como $\pi \alpha \rho \alpha ́ \delta \varepsilon 1 \sigma o \varsigma$ (y traducida al latín como paradisus), en acadio como pardesu, en hebreo como pardes (Nehemias 2:8; Eclesiastés 2:5; Cantar de Salomón 4:13), en armenio como partēz y en árabe como ferdaws (Corán 18.107, 23.11), y cuyo significado etimológico es literalmente «recinto».

El término elamita partetaš también está atestiguado en el sentido de «jardín» o «huerto» en la PFa 33 donde se registran 6.166 árboles frutales plantados en cinco diferentes lugares, donde tres de ellos son señalados específicamente como partetaš; la PF 158 menciona concretamente un partetaš como la ubicación de una plantación de dátiles (kirima en elamita) y probablemente también en las PF 144-149 donde cinco partetaš son mencionados como un lugar de almacenamiento de higos, dátiles, granadas, melocotones y albaricoques. Igualmente, la PF 1815 registra raciones para cuatro inspectores de madera-zappan en el partetaš de Parsaraš. De este modo los partetaš figuran también como lugares de almacenamiento para productos naturales (en recepción de impuestos) en los textos del Archivo de la Fortificación de la serie C1. Las mercancías (dátiles, albaricoques, manzanas y granadas, y varios tipos de grano) se distribuirían en su momento para el consumo, aunque donde y a quien no es normalmente declarado ${ }^{13}$. Además, el partetaš es el lugar más frecuentemente mencionado como lugar de almacenamiento en textos de este tipo. Los otros casos son fortalezas (PF 159-160), una hacienda (PF 180) y un cobertizo (PF 331), y en la mayoría de los casos nos encontramos con un topónimo. Es difícil saber, en todo caso, lo que se deduce de esto, aunque es bastante probable que algunos de los topónimos ocultaran la localización de un partetaš.

También hay que tener en cuenta que en una ocasión una oveja es suministrada para la celebración de una ceremonia lan en el partetaš de Pasargadā (PF-NN

(Nupištaš), 1178 (Abbadaraš), 1439 (Barašba), 1455 (Akkuban), 1505 (Nupištaš), 1981 (Kutkuš), 1991 (Mamakaš), 2141 (Nupištaš), 2445 (Nupištaš). Otros textos mencionan partetaš en Persépolis (PF-NN 2280), Pasargadā (PF-NN 2259), Parsaraš (PF 1815 y PF-NN 1368), Hardarizza (PT 1963-1969), Appištapdan, Tikranuš y Pirdubatti (PFa 33), Vispašiyātiš (PT 49 y 59) y dos partetaš sin nombre (PFNN 1612, PT 48). En la PF-NN 260 una mercancía es tomada desde Datapparna a Kukkannaka para cuatro lugares. Tres son conocidos por albergar un partetaš (Murkaziya, Matannan y Parsaraš), aunque es dudoso que esto justifique la localización de un partetaš en la cuarta, es decir, en Tirazziš = Šìrāz.

13. Se observa a grupos de trabajadores recibiendo raciones, así como grupos de muchachos, mujeres y un grupo variado interpretado como coperos o chipriotas. Para más información véase Ch. Tuplin, 1996, 95.
2259). En todas las demás referencias, sin embargo, esta palabra indica una producción de grano (PF 150157) o una casa de cría de ganado ( $P F$ 1815, raciones para cuatro controladores de lana... con 285 cabras). ¿Por qué entonces esta palabra fue tomada por las lenguas occidentales para tener un significado diferente? Si un partetaš es igual a un $\pi \alpha \rho \alpha ́ \delta \varepsilon 1 \sigma o \varsigma$ lo que nunca revelan los textos del Archivo de la Fortificación son las características del $\pi \alpha \rho \alpha ́ \delta \varepsilon 1 \sigma o \zeta$ mencionado por la historiografía griega; y si la conclusión es que un $\pi \alpha \rho \alpha ́ \delta \varepsilon 1 \sigma o \varsigma$ persa puede ser un lugar de almacenamiento, un centro de trabajo e incluso relativamente humilde, entonces que así sea. Precisamente porque * paridaida es una palabra de etimología no especifica no deberíamos realizar suposiciones acerca de la gama de fenómenos que podía abarcar.

El análisis de la utilización del término partetaš en el Archivo de la Fortificación parece demostrar que se trataba probablemente de una hacienda privada o real (elamita irmatam) cultivada por grupos de trabajadores (elamita kurtaš) a través del sistema de servicio de trabajo obligatorio. Este sistema de explotación de la tierra en la producción de grano había dejado de existir en Mesopotamia a finales del III milenio a.C., y en Siria y Asia Menor a finales del II milenio a.C., siendo reemplazado por el alquiler de parcelas de tierra a pequeños propietarios. Las tierras en el Fārs fueron administradas por sus propietarios de una forma centralizada, como unidades individuales que se convirtieron en los parques de vida salvaje de los nobles persas, o en los jardines frutales y las plantaciones de dátiles cultivadas por esclavos (Uchitel, 1997, 141). Este fue probablemente un fenómeno relativamente nuevo que necesitó de una nueva palabra. No es de extrañar que la palabra que se encuentra en la época meda, como la del periodo aqueménida llegaran también a las lenguas «occidentales» (griego, hebreo, licio, arameo) en su forma meda, aunque es irónico que se originara en el contexto del sistema más arcaico de la tenencia de la tierra que aún sobrevivía en las satrapías iranias del Imperio de los aqueménidas (Uchitel, 1997, 141).

Además, muchos de los topónimos mencionados en el Archivo de la Fortificación de Persépolis, algunos de ellos señalados específicamente por contar con un partetaš y por estar relacionados con la institución de la mesa del rey, son nombrados en más de un año, lo que sugiere que estos lugares podían tener instalaciones permanentes para acoger al monarca. Es tentador pensar en los «pabellones» que se acaban de mencionar como las residencias de los monarcas y de los altos dignatarios de la corte en estos partetaš. Aunque los datos arqueológicos precisos para la mayoría de estos sitios son escasos, y aunque el tamaño y la configuración de las estructuras pueden tener diferencias de un sitio a otro, el uso de las bases de columna de piedra señala una utilización por parte de una elite o de la propia realeza. Pueden haber sido residencias o estaciones reales lujosas, en definitiva, estructuras palaciegas que se utilizaron en combinación con el campamento 
real durante la visita del soberano ${ }^{14}$. Además, como manifestaciones permanentes de la presencia y de la autoridad real, habrían transmitido un mensaje ideológico, aunque como el resto de las estaciones, también incorporaron funciones administrativas y económicas. Por este motivo, es necesario un estudio mucho más profundo sobre estos establecimientos, ya que la documentación arqueológica referente a Irán, y también al Asia Central durante el periodo aqueménida, sigue siendo muy incompleta, dispar, poca y muy desigualmente publicada y a menudo poco accesible.

Como hemos visto, junto a estas suntuosas instalaciones, también existieron estaciones de características modestas, que evidentemente, serían mucho más numerosas que las anteriores. Los escasos vestigios arqueológicos sugieren que eran instalaciones bastantes simples, con un espacio central de donde salían 5 habitaciones de similares dimensiones. De todas formas no se puede descartar la hipótesis de la existencia de una habitación de mayores dimensiones y mejor preparada ante la posibilidad de la llegada de un alto funcionario, de un personaje de cierta importancia o del propio monarca, ya que es inconcebible la existencia de numerosas estaciones de características palaciegas. A su vez existirían habitaciones más modestas, donde se podía pasar la noche, destinadas a los viajeros, a los mensajeros y a los empleados que desempeñaban su labor en la estación.

Estas instalaciones debieron de contar también con sus propios establos, donde los viajeros o los mensajeros a caballo podían cambiar de montura y seguir su trayecto. Cómo eran estos establos es otra cuestión difícil de dilucidar por la falta de datos disponibles, por lo que cualquier reconstrucción es meramente circunstancial, aunque es muy probable que éstos fueran de madera. Se puede sugerir, de manera general e hipotética, que el establo debería estar construido sobre un suelo firme y sólido, con buen drenaje del subsuelo para que se evitara la humedad del suelo. Además, debería de estar ubicado en un terreno moderadamente alto y abierto, con facilidades para el drenaje natural, y orientado no sólo con el fin de recibir buena luz y tener acceso al aire libre, sino para evitar los más severos

14. El rey en sus desplazamientos transportaba el centro político y administrativo del Imperio en la forma de un gran campamento, bien organizado en cada parada, incluida la tienda del rey en el centro, totalmente equipada con una sala para los banquetes, con el apoyo de 30 postes de $15 \mathrm{~m}$ de altura, apartamentos con cuartos de baño, oficinas, etc. Esto es debido a que el poder estaba donde se encontraba el monarca, es decir, durante la duración del viaje, la tienda real es el lugar donde el poder es ejercido por el Estado. Además, también hay que añadir a la tienda real la de los nobles, «padres» y «amigos», por no mencionar las dedicadas a la producción y a la conservación como los archivos, cocinas, establos, etc. Todos estos grupos viajan con su equipamiento correspondiente a su modo de vida o a las necesidades de su función. El centro de poder de la dinastía aqueménida es, por lo tanto, cuando se viaja, una ciudad real de tiendas de campaña. vientos del invierno que soplan directamente contra los edificios. El diseño del establo dependería del terreno y del espacio disponible, aunque cualquiera de los planos debería de tener un suministro de aire y luz adecuado, con ventanas y puertas, preferiblemente dispuestas, al final de ambas paredes. Pequeños recintos son peores modelos puesto que ofrecen un suministro de aire menos perfecto y una mayor probabilidad de contagio en caso de enfermedad. Del mismo modo, cada puesto requeriría básicamente el espacio suficiente para que el animal pudiera moverse, acostarse y alimentarse sin perturbaciones.

Se podría indicar de manera muy hipotética que los establos asociados a estas estaciones reales aqueménidas, en aras de la eficiencia, estarían formados por una estructura formada por dos líneas de puestos y un pasillo central, con facilidades para la alimentación y la ventilación. Los pasillos laterales con toda seguridad estarían adoquinados o enlosados, mientras que el pasillo central debería mantenerse limpio y libre de polvo. Además el subsuelo debía de tener un buen drenaje y debía de estar bien estabilizado para soportar el peso del movimiento de los caballos. El tamaño total del edificio, es decir, las dimensiones interiores adecuadas del establo, debería de ser de entre 7,60 a $11 \mathrm{~m}$ de ancho y, para un conjunto de 20 caballos, de entorno a 15,25 a $18,30 \mathrm{~m}$ de largo. Cada compartimento individual debería tener una anchura de entre 1,5 y 2 $\mathrm{m}$ y una longitud de entre 2,75 a $3,35 \mathrm{~m}$, contando además con un pesebre para alimentar al animal, estando separados de los otros puestos por barras o vigas. Las puertas, probablemente, sólo se encontrarían en un extremo de la construcción, con ventanas a ambos lados de la puerta para proporcionar una adecuada ventilación del recinto. Serían pues estructuras muy simples pero que protegían a estos animales de la lluvia, el viento y la nieve (Fig. 12). Como se ha indicado, esta reconstrucción es meramente hipotética, y solo futuros hallazgos podrán arrojar luz sobre estas construcciones y su asociación con las estaciones reales. Lo cierto es que el sistema de correos aqueménida necesitaba que los caballos se encontraran en las mejores condiciones para que el sistema funcionara correctamente, por lo que éstos, además de ser muy bien alimentados, tal y como evidencian los textos del Archivo de la Fortificación de Persépolis, deberían de vivir en unas instalaciones apropiadas, de otro modo, hubiera sido imposible que el sistema funcionara de manera eficaz.

Asimismo, como se desprende de la documentación, un almacén y depósitos de agua debieron de ser instalados para atender las necesidades tanto de los viajeros y de los animales que los acompañaban, así como de los propios empleados de la estación. Del mismo modo, también tuvo que existir un archivo donde se guardaban las tablillas y los documentos que registraban la contabilidad de la estación, esto es, los productos recibidos y las mercancías entregadas a modo de ración a las personas que presentaran la pertinente documentación oficial, tal y como evidencia el Archivo de la Fortificación de 


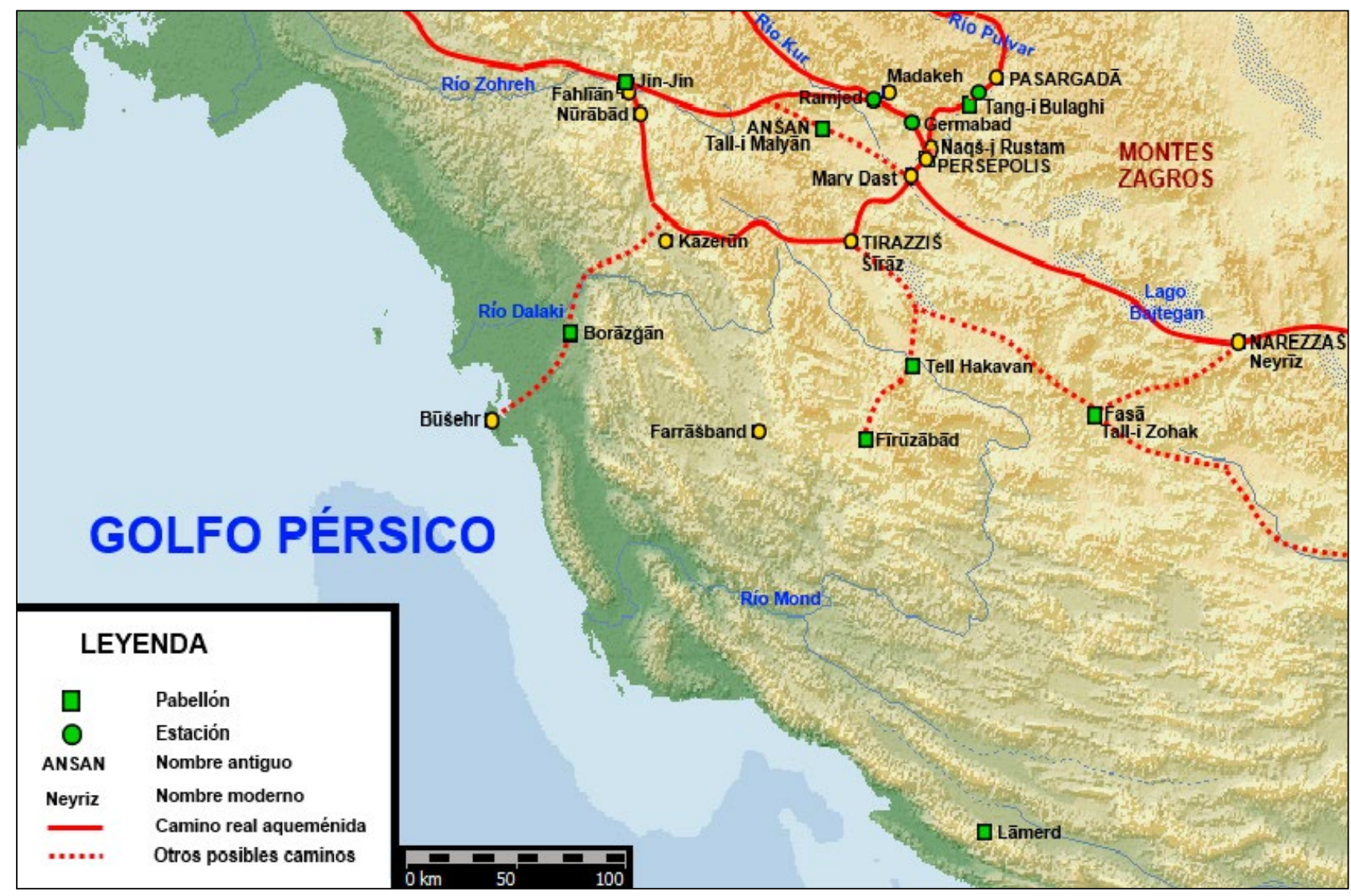

Figura 11: Pabellones y estaciones localizados en el Fārs.

Persépolis. Además, según se desprende de los textos de este mismo Archivo se requirieron también salas específicas en estas estaciones, ya que se menciona también el procesamiento local en algunas estaciones, como por ejemplo la elaboración de la cerveza, la molienda del grano, etc.,. Este último punto es interesante teniendo en cuenta los hallazgos efectuados en la estación de Qalēh-ye Kalī (Jin-Jin), donde se incluyen piedras de molino y grandes recipientes de almacenaje (Potts et alii, 2007, 297-298). Tampoco se puede descartar la idea de que algunas de estas estaciones constituyeran auténticas aldeas o pueblos, que como consecuencia de su alta actividad, necesitaran de mayores recursos y por ello de una población e instalaciones permanentes. Como se observa en el Archivo de la Fortificación de Persépolis, algunas estaciones distribuyen y reciben materias primas de otros centros, por lo que no es aventurado pensar que algunas de estas instalaciones se convirtieran en aldeas e incluso en auténticas ciudades. Por ejemplo, la anteriormente mencionada Hidali, entrega 200 BAR de grano-tarmu a la estación de Kesat en el año 23 de Darío (PF 35), mientras que a su vez es suministrada por la estación de Hunar en el año 17 con 1.470 BAR de grano (PF-NN 574) y en el año 18 con 3.630 BAR de grano-tarmu (PF 200). Estos ingresos y salidas evidencian la importancia que Hidali tenía en esta época. Ejemplos similares se pueden observar en lugares que son descritos por entregar raciones a los viajeros en el Archivo de la Fortificación de Persépolis.
En cuanto al personal a cargo de las estaciones, su número variaría en función del tipo de estación. Es evidente que una estación con características suntuosas requería de un personal mucho más numeroso y especializado que otras instalaciones más modestas. Pero en general, podemos suponer que, además de los funcionarios encargados de la gestión de ésta (suministradores de grano, repartidores, escribas), debían convivir también con los trabajadores propios de la estación (cuidadores de caballos, cocineros), mensajeros, siempre preparados para revelar a sus compañeros, y soldados, encargados de velar por la seguridad de los viajeros y de mantener la paz a lo largo de los caminos reales.

A modo de resumen final, sobre los caminos reales aqueménidas, se implantaron una serie de estaciones donde los mensajeros, funcionarios, cortesanos o viajeros podían alimentarse, descansar y cambiar de montura para poder proseguir el trayecto sin problemas, siempre y cuando presentaran el documento oficial sellado que garantizaba el disfrute de tales ventajas. Estas instalaciones estaban separadas, por regla general, por un día de marcha, donde la distancia variaría como consecuencia de las condiciones orográficas del terreno. Mayor distancia cuando las condiciones eran favorables, y menor longitud cuando éstas eran menos propicias (zonas montañosas, desiertos, etc.). A raíz de los hallazgos arqueológicos podemos sugerir de manera general la existencia de dos tipos diferentes 


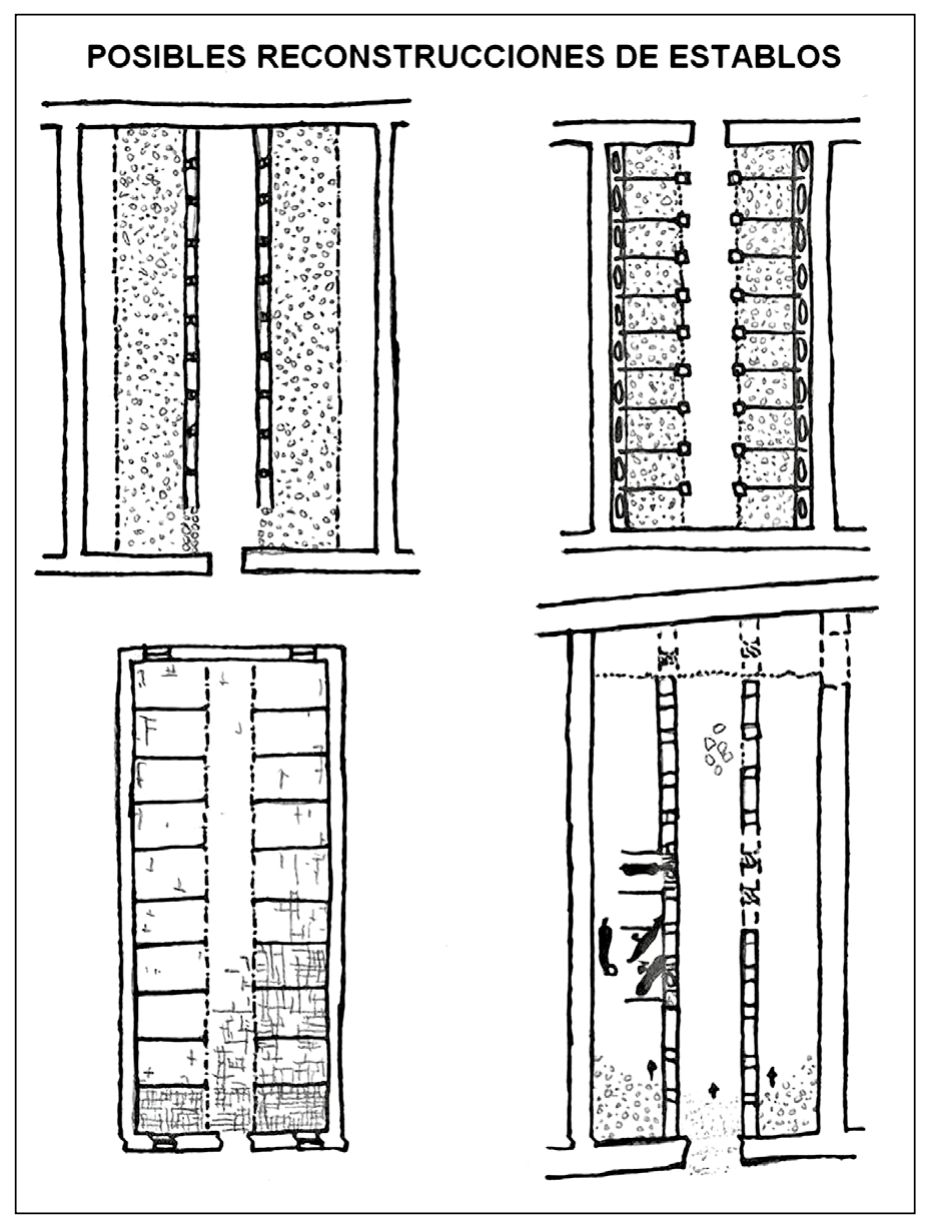

Figura 12: Posible reconstrucción de los establos.

de estaciones: unas más lujosas, destinadas a la élite aqueménida, y otras de características más modestas, y por ello, dirigidas a individuos de menor rango social. Todas estas características del sistema viario no difieren en nada de lo que nos encontraremos en periodos posteriores. Es la prueba de que las mismas necesidades requieren de los mismos medios, sin que se pueda siempre inferir la influencia de las instituciones antiguas sobre las que se crearon con posterioridad.

$$
\begin{aligned}
& \text { Dr. Joaquín Velázquez Muñoz } \\
& \text { Calle Alfonso XII, 63, } 8^{\circ} 2 \\
& \text { 28938 Móstoles (Madrid) } \\
& \text { joaquinvelazquez1982@gmail.com }
\end{aligned}
$$

\section{BIBLIOGRAFÍA}

ABDI, K., 2001: «Malyan 1999», Iran, 39, 73-98.

ADACHI, T. y ZEIDI, M., 2009: «Achaemenid and postAchaemenid remains from TB 75 and the general survey of the Tang-i Bulaghi», ARTA 2009.002, 1-8.

ATAI, M. y BOUCHARLAT, R., 2009. "An Achaemenid pavilion and other remains in Tang-i Bulaghi», ARTA 2009.005, 1-33.

ATARASHI, K. y HORIUCHI, K., 1963: Fahlian, I. The Excavation at Tape Suruvan, 1959. The Tokyo University
Iraq-Iran Archaeological Expedition, Report 4, The Institute for Oriental Culture, Tokio.

ASADI, A. y KAIM, B., 2009. «The Achaemenid building at site 64 in Tang-e Bulaghi», ARTA, 2009.003, 1-20.

ASGARI CHAVERDI, A. R., 2001: «Fārs pas az darius-e sevvom: nowyāfte-ha-ye az yek mohavvate-ye bāstāni dar Lāmerd-e Fārs» [El Fārs después de Darío III: descubrimientos en el sitio antiguo de Lāmerd, Fārs], Iranian Journal of Archaeology and History, 13, 2/14, 1, Ser. 26-27, 66-71.

ASGARI CHAVERDI, A. R., 2002: «Archaeological Reports. Recent Post-Achaemenid Finds from Southern Fars, Iran», Iran, 40, 277-278.

BOSS, A. P. 1991: «Supplementary notes on the 'De Mundo'», Hermes, 119, 312-332.

BOUCHARLAT, R., 2005: «Iran», en P. BRIANT y R. BOUCHARLAT (Eds.), L'archéologie de l'empire achéménide: nouvelles recherches, Persika 6, 221-292, Paris.

BOUCHARLAT, R., 2013: «Southwestern Iran in the Achamenid Period», en D. T. POTTS (Ed.), The Oxford Handbook of Ancient Iran, 503-527, Oxford.

BRIANT, P., 1991: «De Sardes à Suse», en H. SANCISIWEERDENBURG y A. KUHRT (Eds.), Achaemenid History 6: Asia Minor and Egypt: Old Cultures in a New Empire, 67-82, Leiden. 
BRIANT, P., 1996: Histoire de l'empire perse de Cyrus à Alexandre, Paris.

CALLIERI, P., 2007: L'archéologie du Fārs à l'époque hellénistique, Paris.

CURTIS, J. E. y TALLIS, N., 2005: Forgotten Empire. The world of Ancient Persia, Londres.

FAZELI NASHLI, H., 2009: «The Achaemenid/Post Achaemenid Remains in Tang-i Bulaghi near Pasargadae: A Report on the Salvage excavations conducted by five joint teams in 2004-2007», ARTA 2009.001, 1-6.

FORBES, R. J., 1934: Notes on the history of ancient roads and their constructions, Amsterdam.

GRAF, D. F., 1994: «The Persian Royal Road System», en H. SANCISI-WEERDENBURG, A. KUHRT y M. C. ROOT (Eds.), Achaemenid History 8: Continuity and Change, 167-189, Leiden.

GREENFIELD, J. C., 1982: «Some notes on Arsham letters», en S. SHAKED (Ed.), Irano-Judaica. Studies relating to Jewish contacts with Persian culture throughout the Ages I, 4-11, Jerusalén.

GRELOT, P., 1972: Documents araméens d'Égypte, Litératures Anciennes du Proche-Orient, Paris.

HALLOCK, R. T., 1969: Persepolis Fortification Tablets, Chicago.

HALLOCK, R. T., 1978: «Selected Fortification Texts», Cahiers de la Délégation Arquéologique en Iran (DAFI), 8, 109-136.

HUFF, D., 1988: «Säulenbasen aus Deh Bozan and Taq-i Bostan», Iranica Antiqua, 23, 285-295.

HUFF, D., 1999: «F̄̄rūzābād», Enciclopaedia Iranica IX, 633-636.

KENT, R. G., 1953: Old Persian: Grammar, Texts, Lexicon, New Haven.

KLEISS, W., 1981: «Ein Abschnitt der achaemenidischen Königsstraße von Pasargada und Persepolis nach Susa, bei Naqsh-i Rustam», Archaeologische Mitteilungen aus Iran, 14, 45-54.

KREFTER, F., 1971: Persepolis rekonstruktionen, Berlín.

KUHRT, A., 2007: The Persian Empire. A corpus of sources from the Achaemenid Period, Vol. I-II, Londres.

LECOQ, P., 1990: «Paradis en vieux perse?», en F. VALLAT (Ed.), Contribution à l'histoire de l'Iran. Mélanges offerts à Jean Perrot, 209-211, Paris.

MACDERMOT, B. C. y SCHIPPMANN, K., 1999: «Alexander's march from Susa to Persepolis», Iranica Antiqua, 34 (=Neo-Assyrian, Median, Achaemenian and other studies in honor of David Stronach II), 283-308.

MINETTI, A. E. E., 2003: «Efficiency of equine express postal systems. Relay riders over two millennia delivered mail with a remarkably consistent alacrity», Nature, 426, 785-786.

MOSTAFAVI, M. T., 1967: «The Achaemenid royal road post stations between Susa and Persepolis», en A survey of Persian art XIV, 3008-3010, Teherán.

MOSTAFAVI, S. M. T., 1978: The Land of Pars. The Historical monuments and the Archaeological Sites of the Province of Fars, Teherán.
MOUSAVI, A., 1989. «The discovery of an Achaemenid station at Den-Bozan in the Asadabad valley», Archaeologische Mitteilungen aus Iran, 22, 135-138.

NYLANDER, C., 1970: Ionians in Pasargadae, Uppsala.

POHANKA, R., 1987: «Zu einigen Architekturstücken von Tell-e Zohak bei Fasa, Südiran», Anzeiger der phil.-hist. Klasse der Österreichischen Akademie der Wissenschaften, 120. Jahrhang 1983, S013. Veröffentlichungen der iranischen Kommission Nr. 14, 20-28, Viena.

POTTS, D. T., ASKARI CHAVERDI, A., PETRIE, C. A., DUSTING, A., FARHADI, F., MCRAE, I. K., SHIKHI, S., WONG, E. H., LASHKARI, A. y JAVANMARD ZADEH, A., 2007. «The Mamasani Archaeological Project, Stage Two: Excavations at Qaleh Kali (Tappeh Servan/Jinjun [MS 46])», Iran, 45, 287-300.

POTTS, D. T., ASKARI CHAVERDI, A., MCRAE, I. K., ALAMDARI, K., DUSTING, A., JAFFARI, J., ELLICOTT, T. M., SETOUDEH, A., LASHKARI, A., AMELI RAD, Sh. y YAZDANI, A., 2009. «Further excavations at Qaleh Kali (MS 46) by the joint ICARUniversity of Sidney Mamasani Expedition: Results of the 2008 Season», Iranica Antiqua, 44, 207-282.

ASADI, A. y KAIM, B. 2009. «The Achaemenid building at site 64 in Tang-e Bulaghi», ARTA 2009.003, 1-20.

RAZMJOU, S., 2005: «Notes on a Forgotten Achaemenid Site at Farmeshgan Iran», en P. BRIANT y R. BOUCHARLAT (Eds.), L'archéologie de l'empire achéménide: nouvelles recherches, Persika 6, 293-312, Paris.

REALE, G., 1974: Aristotele, Trattato sul cosmo per Alessandro, trad. Con testo Greco, introd., comm. e indici, 1974, Napoles.

RUNDGREN, F., 1965-1966: «Aramaica I», Orientalia Suecana, XIV-XV, 75-88.

SILVERSTAIN, A. J., 2007: Postal system in the Pre-Modern Islamic world, Londres.

STEIN, A., 1936: «An Archaeological Tour in the Ancient Persis», Iraq, 3, 111-225.

STEIN, A., 1940: Old routes of Western Iran, Londres.

STRONACH, D., 1978: Pasargadae. A report on the excavations conducted by the British Institute of Persian Studies from 1961 to 1963, Oxford.

SUMNER, W. M., 1986: "Achaemenid settlement in the Persepolis Plain», American Journal of Archaeological, 90, 1-31.

TUPLIN, CH., 1996: Achaemenid Studies, Stuttgart.

UCHITEL, A., 1997. «Persian Paradise: Agricultural Texts in the Fortification Archive», Iranica Antiqua, 32, 137-144.

UGNAD, A. F., 1914: Babylonische Briefe aus der Zeit der Hammurapi-Dynastie, Leipzig.

VELÁZQUEZ, J., 2010. El sistema de caminos reales en el Imperio Persa Aqueménida, Tesis Doctoral inédita. Universidad Complutense de Madrid. 